NIST

PUBLICATIONS

\title{
ESTIMATION OF THE
}

RATE OF HEAT RELEASE

AND INDUCED WIND

FIELD IN A LARGE SCALE

FIRE

\section{T. J. Ohlemiller D. M. Corley}

U.S. DEPARTMENT OF COMMERCE National Instrtute of Standards and Technology

Natlonal Englneering Laboratory Center for Fire Research Galthersburg, MD 20899

Sponsored by:

Defense Nuclear Agency

Alexandrla, VA $22310-3398$

U.S. DEPARTMENT OF COMMERCE Robert A. Mosbacher, Secretary NATIONAL INSTITUTE OF STANDARDS AND TECHNOLOQY

John W. Lyons, Director

QC 


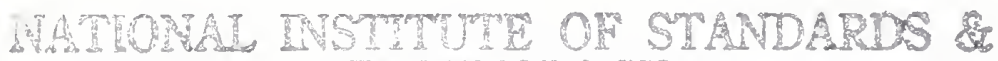
TCONMOTOGX

Research Information Center

Cainhersourn, ND 20899 


\section{ESTIMATION OF THE RATE OF HEAT RELEASE AND INDUCED WIND FIELD IN A LARGE SCALE FIRE}

\section{T. J. Ohlemiller \\ D. M. Corley}

U.S. DEPARTMENT OF COMMERCE Natlonal Instltute of Standards and Technology Natlonal Englneering Laboratory Center for Fre Research Galthersburg, MD 20899

Sponsored by:

Defonse Nuclear Agency

Alexandria, VA $22310-3398$

October 1990

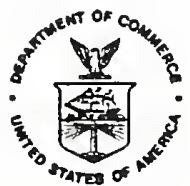

U.S. DEPARTMENT OF COMMERCE Robert A. Mosbacher, Secretary NATONAL INSTTTUTE OF STANDARDS AND TECHNOLOGY

John W. Lyons, Director 

TABLE OF CONTENTS

Page

List of Tables . . . . . . . . . . . . . . . . . . . . v

List of Figures. . . . . . . . . . . . . . . . . . vii-ix

Sumary. . . . . . . . . . . . . . . . . . . . . . . 1

1. INTRODUCTION . . . . . . . . . . . . . . . . . . . . . 1

2. MASS LOSS RATE ASSESSMENT. . . . . . . . . . . . . . 3

3. BURNING AREA VERSUS TIME . . . . . . . . . . . . . 7

4. HEATS OF COMBUSTION. . . . . . . . . . . . . . . . . . . . 9

5. CALCULATION OF HEAT RELEASE RATE . . . . . . . . . . . . . 13

6. PREDICTION OF WIND FIELD . . . . . . . . . . . . . . . 21

7. CONCLUDING REMARKS . . . . . . . . . . . . . . . . 23

8. ACKNOWLEDGEMENTS . . . . . . . . . . . . . . . . 24

9. REFERENCES ....................... . . . . 25 

Table 1. Forestry Canada Data for Pre- and Post-.. . . . . . $26 \& 27$ Burn Slash Fuel Loads in Twelve Sampling Triangles; Hill Township

Table 2. Forestry Canada Data for Pre- and Post Burn . . . . . . . 28 Duff Loading in Twelve Sampling Triangles;

Hill Township

Table 3. Dry Slash Fuel Weight Loss Calculated From. . . . . . $29 \& 30$ Forestry Canada Data; Hill Township

Table 4. Forestry Canada Results for Average Oven - Dry. . . . . . 31 Moisture Content of Various Fuel Classes;

Hill Township

Table 5. NIST Thermocouple Results . . . . . . . . . . . . . . 32

Table 6. NIST Cone Calorimeter Results for Heats of. . . . . . . 33 Combustion of Twig and Duff Samples;

Hill Township

Table 7. Block Al Heat Release Behavior For Model . . . . . . . . 34 Utilizing Constant Mass Loss Rates

Table 8. Block A Rate of Heat Release Behavior for . . . . . . . 35 Constant Mass Loss Rate Model

Table 9. Block A Rate of Heat Release Behavior for a . . . . . . . 36 Simple Exponential Decay Model

Table 10. Block A Rate of Heat Release Behavior for . . . . . . . 37 Alternative Exponential Decay Model 
Fig. 1 Estimate of total burning area in Block Al as a function of time.

Fig. 2 Total burning area in Block A versus time, as determined by NIST and by Forestry Canada from the infrared video tape.

Fig. 3 Layout of instrumentation in Block A relative to 40 roads on site. Darkened, irregular circle indicates first area ignited by heli-torch.

Fig. 4 Example of early burning area spatial distribution in Block A (time is $14: 22: 24$ ). Black dot locates the estimated center of ignition area. Line is used in orienting this pattern relative other features on the burn site.

Fig. 5 Schematic of Block $A$ and Block Al showing approximate boundaries used to break Block Al into three segments based on roughly equal ignition times. Also shown is Birch Lake which was the primary length reference for the NIST analyses of the infrared videotape.

Fig. 6 Total rate of heat release in Block $A$ as a function of local standard time. The three sets of points correspond to the three models, discussed in the text, for estimating the time dependence of the local heat release behavior.

Fig. 7 Comparison of calculated (line with arrow head) and measured (line without arrow head) velocity vectors at Forestry Canada anemometer locations at 14:19:20. Description of Block A1 is being varied in (a), (b), and (c) to improve velocity vector matching. Version (c) is used for model calculations at next two times.

Fig. 8 Comparison of calculated and measured velocity vectors at Forestry Canada anemometer locations at 14:22:24.

Fig. 9 Comparison of calculated and measured velocity vectors at Forestry Canada anemometer locations at 14:25:05. 


\section{•}


Appendix NIST Thermocouple Instrumentation

Fig. A-I Placement of triangles relative to roads in Block A. Darkened triangles had NIST thermocouple instrumentation.

Fig. A-2 Typical layout of NIST thermocouple instrumentation within the confines of a Forestry Canada triangle.

Fig. A-3 Arrangement of thermocouples around a buried datalogger. 50 In the actual placement the two thermocouples shown well above the ground were lowered to a few centimeters to be comparable to those of FC. 



\title{
ESTIMATION OF THE RATE OF HEAT RELEASE AND INDUCED WIND FIELD IN A LARGE SCALE FIRE
}

\author{
T. J. Ohlemiller and D. Corley
}

Abstract

Logging slash on a 486 hectare site in Ontario was burned as part of a Forestry Canada forest management program. A 100 hectare portion of this site was instrumented by several groups interested in large scale fires. The NIST Center for Fire Research utilized Forestry Canada data on mass loading before and after the fire, total burning area as a function of time and burning duration to estimate the spatial and temporal pattern of heat release during the burning of the instrumented section of the fire. Complete information necessary for making this estimate is lacking; the necessary assumptions and their accuracy (when known) are discussed. Heat release rate is reported for three different assumptions regarding the temporal behavior of flaming and smoldering phases of the combustion. This information is utilized in the context of a flow model due to Baum and McCaffrey to calculate the near-ground flow field induced by this heat release pattern and the results are compared to the point measurements made in the field.

\section{1) INTRODUCTION}

Forestry Canada routinely conducts large scale burns of areas of forest which have been logged. These burns clear the area for replanting of trees. The logged area typically has been stripped of all valuable timber but retains some mature standing trees of no commercial value plus logging slash (tree pieces of various sizes from all species growing on the site), immature specimens of all species, a wide variety of brush and the decayed detritus layer on the forest floor (duff). This array of fuel is inherently spatially non-uniform though the practice of "tramping" (systematic compaction of the fuel with a bulldozer) improves this somewhat.

The Defense Nuclear Agency sponsored the participation of several organizations in the study of a 486 hectare burn in Hill Township near Chapleau, Ontario in July, 1989. These agencies included Forestry Canada, the United States Forest Service, the University of Iowa, the University of Washington, Pacific Sierra Research Corporation and the NIST Center for Fire Research.

The current report is limited to the issues discussed in the Abstract above. The overall goal of the present work is an improved understanding of the factors controlling the spread of large fires; this has potential application both to urban and wildland fires.

The overall rate of heat release from such a fire drives the flow which supplies air to the fire. This air flow also plays a major role in the rate of flame spread into unburned fuel areas and thus, in turn, influences the 
rate of heat release. This tight coupling between air flow and heat release must ultimately be unravelled if the nature of large fires is to be fully understood. As a first step in this process, it is useful to know if the flow field can be correctly estimated given the overall rate of heat release at any time. It is necessary to know the spatial distribution of this heat release if one is to properly predict the flow field near ground level where it interacts with the fire [1]. The immediate goal here is then to obtain an estimate of the pattern of heat release at one or more times in the fire that took place in Hill Township. In Section 6 this information will be used in the context of a model for multiple interacting plumes to calculate the nearground flow field; the result will be compared with the flow velocities measured at specific sites during the fire.

The rate of heat release from a large tract of logging slash like that burned in Hill Township is dependent on a large number of factors. Among them are the characteristics of the fuel bed (species distribution, size distribution of the twigs and boles, their moisture content, packing arrangement, the quantity of duff and litter), the terrain (departure from flatness), the ambient weather (wind, humidity) and the ignition pattern. In the case of the particular segment of the burn that is the focus in this study (designated as Block A), there is an additional complication brought on by the fact that this was not the first part of the burn area that was ignited. Block Al, immediately adjacent to Block $A$, was ignited first creating its own wind field which then influenced the burning of Block $A$. As a mnemonic, the reader may wish to note that the number " 1 " in Al stands for "first ignited". Figure 5 shows Block Al in relation to Block $A$; the shaded band between these two areas is their dividing line.

The ignition process is carried out from a helicopter which drops an intermittent string of flaming gelled gasoline. The amount of this fuel is negligibly small and the fire spreads by its own heat release. The ignition process is somewhat protracted, requiring about $3 / 2$ hour in Block Al, for example.

Calculation of rate of heat release is simple, in principle. It is the product of the rate of mass loss, the heat of combustion of that mass and the total area undergoing the mass loss process. However, wood and the other natural fuels present on the burned area undergo not only flaming but also smoldering combustion; the rates and the reaction heats of these two types of processes differ substantially so that it is necessary to keep track of each area undergoing the two processes separately. It is also necessary to obtain a measure of the two differing rates of these combustion processes. As will be seen, this leads to difficulties which add uncertainty to the overall rate of heat release calculation. Because of the uncertainties, the rate of heat release has been calculated in different ways, subject to different assumptions. The techniques that go into estimating the components of the rate of heat release are discussed first, together with the uncertainties that each contains; after this the overall rate of heat release is computed.

Most of the field data used in the calculations discussed here comes from Forestry Canada; NIST supplemented their thermocouple measurements to some extent, as will be briefly described below. 


\section{2) MASS LOSS RATE ASSESSMENT}

There is currently no feasible means to directly measure rate of mass loss in the field during a burn. This would require a pattern of weighing platforms to somehow be inserted under a minimally disturbed forest floor. Instead the total mass loss (flaming plus smoldering) is sampled at several locations by a planar intersect technique, well before and well after the actual burn [for example, Ref. 2]. Sampling at several locations is necessitated by the nonuniform spatial distribution of the logging slash on the burn site. As implemented by Forestry Canada at Hill Township, sampling was done at twelve triangular plots, each thirty meters on each side (locations shown in Fig. 3). On each side of a triangle counts are made, in a fixed pattern, of the number and size of twigs and boles that cross an imaginary vertical plane containing that side of the triangle. Such counts have been correlated with the volume of woody material within the triangle. From this volume and an estimate of the species distribution (and thus the wood density distribution), the dry mass of the wood per unit area in the triangle is calculated. Reference 2 indicates that standard practice with this sampling technique yields the local mass loading to an accuracy of \pm 208 . It is not known if there were a sufficient number of intersections with the counting planes of all the triangles after the burn to maintain this level of accuracy. The water content of the wood is sampled separately; it varies with the diameter of the wood.

The forest floor is covered by a layer of decaying debris (needles, leaves, twigs) called duff whose density and water content increase with depth. This layer contributes substantially to the net mass loss during the burn, both by flaming and by smoldering. Its mass before and after the burn is assessed by means of layer depth change sampling, done along the sides of the triangles described above. Depth is translated to dry mass per unit area by means of a standard density profile developed for the local region, though not for the actual burn site in Hill Township. The water content of this duff layer is sampled at two depths.

The results of the above techniques are summarized in Tables 1 and 2 which give the dry mass loading before and after the burn. The results are broken out by size class for reasons which will be explained below. Note that the results from the twelve triangles are separated into three groups (1-4, 5-10, 11-12); there were significant differences in the fuel loading or the nature of the terrain among these three groups. Aside from discarding the results for triangles 11 and 12 in all averages used here (these were in an exceptionally wet area), the noted differences were not accounted for in the calculations of heat release pattern described below. It should be noted that in Tables 1 and 2 , as well as elsewhere, we report data as received from Forestry Canada to a larger number of significant figures than can be justified by the various uncertainties that are discussed here.

These sampling techniques cannot distinguish in which stage of combustion, flaming or smoldering, the mass was lost. In the slash, flaming tends to extensively consume mainly those materials (small diameter twigs, needles, 
leaves) which are thermally thin (i.e., pieces of fuel which are heated all the way to their center during the time of passage of the flame front). Large pieces that are thermally thick (not significantly heated at their centers) will flame longer only if they are close to other flaming material with which they can exchange radiation. (Close here means about one diameter away.) Large pieces, not satisfying this closeness or packing requirement, will undergo minimal mass loss during flaming. Intermediate sizes will undergo moderate flaming mass loss. Among the slash portion of the fuel, one would expect similar size dependence for the smoldering stage of combustion, for similar reasons.

There could be some dependence of the details of this size dependent behavior on species. Density and thermal properties, for example, which could affect this behavior, vary with species. Packing density could also play a role. There is also the apparently unique behavior of balsam fir; large diameter boles of this wood tend to be fully consumed even when they are not near other boles [3]. The mechanism behind this remains mysterious to this author though it probably involves some interaction with the duff layer. In any event, these points are noted by way of acknowledging the uncertainty introduced by the next step. The flaming and smoldering mass loss in each size class are apportioned in accord with results from Ref. 4 which is based on two other types of wood (Douglas fir and ponderosa pine). That reference shows a monotonic decrease in flaming mass loss with increasing fuel diameter, from 948 for $2 \mathrm{~mm}$ diameter twigs to 118 for $3.5 \mathrm{~cm}$ diameter branches. Forestry Canada has extrapolated this to $4 \frac{8}{8}$ for $5.7 \mathrm{~cm}$ diameter branches and $5 \%$ for all larger diameter material. The accuracy of applying this to the Hill Township burn is not known.

The result of apportioning flaming and smoldering dry mass loss in this way is shown in Table 3. When the results are summed over all size classes and averaged over triangles 1-10, one finds for the slash loss by the two combustion stages: ${ }^{1}$

$$
\begin{aligned}
\text { flaming: } & 0.90 \pm 0.19\left(\mathrm{~kg} / \mathrm{m}^{2}\right) \\
\text { smoldering: } & 6.6 \pm 1.3 \quad\left(\mathrm{~kg} / \mathrm{m}^{2}\right)
\end{aligned}
$$

Note that there is a surprising dominance of weight loss by smoldering; also note that 5.0 of the $6.6 \mathrm{~kg} / \mathrm{m}^{2}$ smoldering mass loss is in the $>7 \mathrm{~cm}$ diameter size class. The explanation for this latter result is not clear.

The Forestry Canada data on the water content of the various fuel classes are given in Table 4; the results are reported as weight percent of oven-dry fuel weight. Some of this water is also vaporized during the burn but no data are available on how much. Since this water vaporization is strongly endothermic,

\footnotetext{
${ }^{1}$ The results from triangles 11 and 12 are omitted from this averaging process since they represent a relatively small area of the burn site which was exceptionally wet.
} 
it affects the overall combustion heat. The discussion of this is deferred to the section below on heats of reaction.

The preceding data on mass loss by the two combustion modes must be coupled with combustion time information in order to infer the rate of each process. This too is problematical. Both Forestry Canada and NIST placed thermocouples in the burn area in association with the triangles used for mass sampling (see the Appendix for details of the NIST installations). These thermocouples record the local temperature, whether in the region just above the duff or in the duff layer itself. It requires some separate decision basis to determine whether the temperature is the result of flaming or smoldering. The extent of the ambiguity is illustrated by the NIST thermocouple results summarized in Table 5. Tabulated there in the second column are the average times ( \pm std. dev.) spent above the indicated temperatures for thermocouples above the duff layer. If one takes this time as the local flaming duration, the data in this column indicate an uncertainty in the flaming duration from 149 to 544 seconds, a factor of 3.6. The third column of data pertains to thermocouples placed in the duff layer. It has the decay time to reach $100{ }^{\circ} \mathrm{C}$ (after the temperature has dropped from its peak value to the value indicated in the first column). If this is taken as a measure of the local smoldering duration, the data imply an uncertainty of about a factor of two.

In order to lessen these uncertainties about burning duration, Forestry Canada utilized the video tape from inside the fire obtained by Pacific Sierra Research Corporation (PSRC). By examining this tape they concluded that the flaming duration was 3.2 minutes. Comparing this value with their own, more extensive thermocouple data, they concluded that temperatures above $700{ }^{\circ} \mathrm{C}$ corresponded to flaming. With this one point assigned, they then took the decay time from $700^{\circ} \mathrm{C}$ to $200^{\circ} \mathrm{C}$ in their thermocouple signals as the smoldering duration. The inferred smoldering duration in the slash layer was 22.1 minutes; in the duff layer it was 30 minutes.

We have undertaken a systematic study of the available video tapes from inside the fire, for similar reasons. To do this a simple, transparent mask was created for each tape which, when applied over the face of the TV monitor, broke the field of view into a number of rectangular areas, of the order of a few square centimeters, which could be carefully viewed, one at a time. From the geometry of the camera set-up in the field one can estimate that the areas on the ground being viewed in this manner were typically several meters on a side. As the video tape from a given site was played, an observer focused on one of the rectangular areas and recorded his estimates at successive times of the fraction of that area which was occupied by flames originating in that area. Since there is a subjective element to these estimates, two observers were used for several of the viewed areas.

This procedure was applied to the PSRC tape and to three University of Iowa tapes (their sites 3 and 5 plus the PSRC spread array area). The data from site three were discarded since the flames were extraordinarily hard to see. Smoke obscuration was a problem with all of the other tapes as well; the fuel bed could be seen only at infrequent intervals in some of the tapes. In general, one could see that some flaming continued for long durations (ten to twenty minutes or more) but the fraction of any given area that was involved 
in flaming decayed rather rapidly with time. We have chosen the $50 \%$ flaming fraction point to characterize the flaming duration; our result is $4.0 \pm 2.3$ minutes. Since a large fraction of the local rate of flaming heat release occurs early in the flaming interval as the fine fuels burn rapidly, it is quite probable that the well over $50 \%$ of the total flaming heat release occurs within this time interval (at least for the thermally thin material; the fate of the thermally thick material is ambiguous).

It should be noted that both the Forestry Canada and NIST values for flaming duration appear to be compatible with mass loss rate data provided by the United States Forest Service (USFS). The USFS has taken a completely different approach to assessing mass loss rate. Their technique is based on measuring the carbon flux from the fire in one area. While the technique has been shown to capable of 10-158 accuracy in laboratory studies [5], the accuracy achieved in the field is much harder to assess. The actual sampled area would seem to vary as the wind fluctuates in intensity during the fire's passage. In any event, we have made use of the inferred rate curve to evaluate a characteristic mass loss rate parameter in some of our calculations below.

Our study of the video tapes from inside the fire has lead us to try more than one approach in calculating overall rate of heat release, as will be seen below. The tapes point out the tenuous nature of the concept of flaming duration. They also raise doubts about the value of point measurements by thermocouples in the slash layer; the fuel bed characteristics vary too abruptly from point to point to be truly characterized by anything less than a very large number of thermocouples.

The video tapes cannot provide any information on smoldering duration. We have used the Forestry Canada values in some of the calculations below, particularly for the duff layer. The accuracy of these numbers is difficult to assess without some sort of field study that focuses on the details of both slash and duff smoldering. In particular, the use of the thermocouples assumes that the duff layer smolders from the top down in a one-dimensional manner. This is probably true for some substantial fraction of the duff but in other duff areas the smolder may be propagating in a two or threedimensional manner. Such propagation would greatly slow the local duff smolder rate.

The mass loss and burning duration results are used to infer mass loss rate due to both flaming and to smoldering, separately. The simplest way in which to do this is to assume that the rate is constant in a given area for the inferred flaming time and then for the smoldering time. Since the burn area is increasing during the time of interest due to continuing ignition and flame spread, the choice of what area to apply such a concept to is not straight forward; this issue will be discussed below. This constant rate idea has been used effectively in the past by McRae and Stocks [6]. On the other hand, Ward and Hardy [7] found that the mass consumption rate in a series of small, undisturbed test plots (covered with logging slash) exhibited an exponential decay with time after an initial build-up period associated with flame spread. Both of these concepts are utilized in the rate of heat release calculations 
presented below, in order to test the sensitivity of the results to the mass consumption rate model.

\section{3) BURNING AREA VERSUS TIME}

The second element in the rate of heat release calculation is the area undergoing a specific combustion process, flaming or smoldering. Recall that our ultimate goal is to calculate the fire-induced flow field and this is affected both by the growing fire in Block A (instrumented block) and the decaying fire in Block Al (block ignited first). Thus this area information is needed for both blocks of the fire.

In this type of fire, virtually all of the increase of burn area with time is due to the spreading of flames; the fraction of total area that is directly ignited by the helicopter torch is negligibly small. The spread process fills in the area between the lines of ignition. In Block Al, for example, most of these lines were roughly parallel, running approximately north-south. The fill-in process there, via flame spread, took only a few minutes, once the lines were laid down in a given section; the substantial ambient wind from the west undoubtedly sped this process.

A Forestry Canada helicopter with a infrared imaging camera has provided detailed data on the time-dependent spread of the burn area in Block A, but the data in Block Al are more sketchy. Furthermore, there are significant limitations on the infrared data for the whole burn. The camera has a minimum spatial resolution of about $2 \frac{1}{2}$ meters at its typical altitude of 2500 feet. Since such a camera will not correctly measure the emission intensity of objects unless they are a few times larger than this resolution limit, this means that brightness variations due to localized flaming and smoldering areas on a scale of several meters in diameter will be blurred and indistinguishable from each other. It also means that the edges of the burn area will be blurred somewhat. This limit to the spatial resolution is not a major source of error. ${ }^{2}$ Surprisingly, it seems inconsistent with the fact that essentially no spatial variation in brightness was visible on the IR burn area images, even on much larger, readily resolvable scales until an area had been burning for many minutes. Thus the IR images did not provide a distinction between flaming and smoldering areas during the time of interest. The underlying reason for this is not clear. It implies that the whole burn area was equal in temperature, on the resolvable spatial scale. This cannot be literally true but it adds support to the idea that flaming persists in a significant fraction of the burn area well after the spreading flame front has passed.

There are two other significant sources of uncertainty about the IR images. First is the calibration with regard to actual length on the ground. Since the use of glowing markers on the ground was not successful, the length

2 This resolution limit does defeat the idea of using small smoldering charcoal buckets as ground position markers. Small sources will show up only if they are much brighter, e. g., a $\mathrm{CO}_{2}$ laser. Even then, their position cannot be known more accurately than the spatial resolution limit. 
calibration basis for the NIST interpretation of the IR tape comes from one brief sequence in which Birch Lake is weakly visible on the tape. The length of this lake, taken from a Provincial map, is 451 meters in its longest direction. Forestry Canada, using a separate calibration obtained previously, has determined that the length of this lake in the infrared image is 480 meters. The source of this discrepancy remains unclear; it is conceivable that the infrared image shows more than just the body of water. The other source of uncertainty comes in the image analysis of the IR tape. At NIST this was done using a commercial system designed for the digitizing and quantitative analysis of infrared images. NIST and Forestry Canada get somewhat differing results for the total burn area in Block A as a function of time, quite apart from the issue of length calibration. This appears to be due to differing brightness thresholds used to determine whether a pixel on the image is burning or not. The proper threshold value is not obvious due to the blurring of the edges of the burn area, noted above, and to the presence of glowing flames or soot extending beyond the actual ignited area in many of the images. Also, in some of the images, water vapor appears to be partially obscuring some of the burning area, modulating its apparent brightness.

As noted above, the burn area versus time for Block Al is sketchy, at best. Figure 1 shows the result of our image analysis. The very limited number of points is due to the fact that no other relatively complete IR images of this area are available in this time interval. The uncertainties shown on each measured area are mainly the result of the fact that the full burn area was not visible. Note that there is some uncertainty, as well, in the value of the full burn area for Block Al due to two differing sources of the measurement. Figure 1 implies that shortly after the start of the ignition of Block A, the burn area of Block Al reached its full value. (A value of 60 hectares was actually used here to allow for some edge region around the Al periphery where the flames spread slowly against the incoming wind.) No further good images of Al are available in the next fifteen minutes or so (the time interval of interest for calculating the flow field in Block A), but it appears to be adequate to assume that during this entire time interval when Block $A$ is the focus, Block Al is burning over its entire area ( 60 hectares). However, since Block AI was ignited over an interval of about 25 to 30 minutes, the state of the combustion process is not uniform throughout this area and this must be taken into account, at least approximately. To do this Block Al was broken into three segments, each of which had, within its borders, a relatively small variation in absolute time of flaming ignition. The entire area in each of these three segments was treated as if it was ignited at the same time and behaved uniformly with regard to heat release rate, as will be seen below.

Figure 2 shows the NIST and Forestry Canada results for the variation of total burning area in Block $A$ versus time. The differences shown in the two results do not include the length calibration discrepancy mentioned above since it is uncertain which set of results is incorrect in this respect. (The nature of that length discrepancy is such that it would force the two sets of area measurements further apart, no matter which set is in error.) It is apparent that the total Block $A$ burn area increases dramatically in only about fifteen minutes, approaching the level of Block Al in this time. Again this is virtually all due to flame spreading from the minute, but constantly 
increasing area directly ignited by the heli-torch. The pre-existing wind out of the west is being supplemented by the flow induced via the burning of Block Al whose placement to the east of Block A makes these two effects additive; the net effect was a strong tendency for rapid flame spread from east to west in Block A during this time interval.

It should be noted that the heli-torch ignition pattern was changed for Block A. Rather than proceeding in a series of roughly parallel lines as for Block Al, the helicopter ignited the area in a series of concentric circles or spirals. The center of these was very near triangles 9 and 10; see the map in Figure 3. (The placement of the center of the Block A ignition pattern is due to Forestry Canada; it was inferred from the IR tape but there is some uncertainty, difficult to quantify, in this placement. It is quite near the planned starting point.) Figure 4 shows the shape of the total burn area at an early time in the Block A ignition process.

In utilizing the above results for burn area at any given time, it is necessary to make some judgement about which portion is flaming and which is smoldering; as noted above, the IR tape cannot help in this separation. In previous work, McRae and Stocks were able to make this separation by keeping track of the spreading flame fronts for burn areas ignited in a series of parallel strips [6]. In the present case, due to the spiral ignition pattern coupled with the strong, one-sided wind field, the flame fronts move in a manner that is hard to follow quantitatively.

Here we make use of the idea of a characteristic flaming time, which derives from the fact, noted above, that the increase in burn area in any time interval chosen in Figure 2 is due to flame spread. In one interpretation of this idea it is assumed that only the new area generated in the characteristic flaming time is undergoing flaming combustion; the remaining area which is burning is smoldering. In an alternative interpretation of this concept, necessary when the mass consumption process is taken to decay exponentially after flame spread, the new area generated in this characteristic time is taken to be flaming, as before, but the earlier ignited areas have residual flames as well as smoldering. Neither implementation of this idea can be said to be rigorously correct and both suffer from the imprecision with which the characteristic flaming time can be defined. Nevertheless, this appears to be the best that one can do in separating flaming and smoldering in the burn area.

\section{4) HEATS OF COMBUSTION}

Here one needs the effective values of flaming and smoldering combustion heats for both the slash and the duff. Since these values are affected by water vaporization, this needs to be accounted for as well.

The literature is only of limited use. The values reported there are frequently those obtained in an oxygen bomb calorimeter. Such values ignore two important factors. First, the two stages of combustion consume two drastically different fuels: flaming consumes volatile pyrolysis products from the heated woody materials and smoldering consumes the carbonaceous char these 
volatiles leave behind. When there is little or no flaming to char the fuel before the smoldering stage, as happens with the duff, for example, smoldering consumes the original fuel, but not necessarily completely. Second, the efficiency of fuel conversion to $\mathrm{CO}_{2}$ and $\mathrm{H}_{2} \mathrm{O}$ in all of these processes is not 1008 , as it is in an oxygen bomb calorimeter. Susott, et al [8] have demonstrated the difference between the heat content of wood volatiles and wood char; the difference exceeds a factor of two when the oxidation of each is complete. Ward and Hardy [7] report that the overall combustion efficiency in a prescribed burn can range from 60 to 958.

In view of these uncertainties, it was decided to utilize combustion heats measured on a limited number of samples taken from the Hill Township burn site. Samples of the small diameter slash fuels (up to about $1 \mathrm{~cm} \mathrm{dia.)} \mathrm{and}$ of the litter/duff layer were collected on the morning of the burn in the area near the PSRC spread array. The sampling process was not statistically designed to be truly representative but the material did come from several different spots and did include a mix of species. The litter and duff layer material was mixed together in the heat of combustion measurements performed in our laboratory. These measurements utilized our Cone Calorimeter facility which employs oxygen consumption as a means of determining the evolved heat. This measurement technique is generally accurate to about $\pm 5 \%$. It utilizes the fact that the heat evolved per unit mass of oxygen consumed is constant to within about \pm 58 for most organic materials [9]. When the combustion efficiency is not 100\%, as is especially the case for smoldering, a correction is made based on the amount of $C O$ formed, since its heat evolution per unit mass of oxygen consumed is substantially less than for $\mathrm{CO}_{2}$.

The samples are placed in a small metal pan, forming a layer $2-2 \frac{1}{2} \mathrm{~cm}$ deep and $10 \mathrm{~cm}$ square. This fuel layer can be subjected to a uniform incident radiant flux from above during its combustion. This is relevant here since it simulates the heat that might be coming from nearby burning fuel masses. Such additional heat will have some impact on the combustion efficiency.

Table 6 summarizes the results of the NIST measurements of combustion heat. The twigs were tested both with and without an external flux of $2 \mathrm{~W} / \mathrm{cm}^{2}$; this is a level of radiant heat flux that might readily exist in portions of the fuel bed during the prescribed burn. Some enhancement of the combustion heat is seen in the flaming stage when the external flux is present; this enhancement is even greater in the subsequent smoldering stage. The substantially larger heat of combustion for smoldering is consistent with the results of Susott, et al, quoted above; it is a consequence of the high oxygen content of the volatiles burned during flaming as compared to the high carbon content of the char consumed during smoldering. In utilizing these results, values with and without external flux are averaged together, since both situations undoubtedly existed on the burn site (though the proportion of each is impossible to estimate). The duff/litter material, when it flamed, had a quite similar heat of flaming to that of the woody material. Interestingly, however, it would only flame when it was nearly dry and was subjected to an external heat flux. When the water content was higher, the only response was smoldering. Forestry Canada has assumed that the litter layer is fully consumed by flaming. The present results cannot really check this since the litter was mixed into the duff in our samples. We have adopted this same 
assumption in our heat release rate calculations but it is one of several assumptions which probably should be checked in future field studies.

In contrast to the heat of smoldering for the twigs, that of the duff is much lower and the net value decreases strongly with water content of the duff. Since flaming prior to smoldering was minimal or absent, the smoldering process here is consuming the original, highly oxygenated fuel, not a carbonaceous char. The combustion efficiency is also reduced; the co production is as much as a factor of ten higher than during the flaming combustion of the twigs. After correcting for water content, the values from the 7 and $25 \%$ water duff material were averaged and used in the calculations below.

The heat of smoldering of the twigs was also used below for the larger diameter boles of wood. This is very likely an overestimate of the heat of smoldering of these materials since not all of this material was charred extensively by flames prior to the smoldering stage. Wood that is not extensively charred by flames, if it can continue to smolder, could be expected to have a lower heat of smoldering, analogous to the duff. On the other hand some fraction of the larger diameter wood was charred by persisting flames and it is this fraction which should be most likely to continue to smolder due to the assistance of deep pre-heating of the fuel. Unfortunately there is not sufficient information to resolve this issue; closer examination of the behavior of the large diameter boles is needed in future work.

Note that there is no assurance that the combustion efficiencies achieved in the Cone Calorimeter tests are the same as those in the field. There is probably some influence of packing density on combustion efficiency. However, at this point no better values for the effective combustion heats are available.

It was noted above that the water content of the fuel influences the net heat evolved from each burning process and that this must be accounted for in our final assignment of reaction heats. The water content of the fuels before the burn were determined (see Table 4) but the post burn water content was not determined. This necessitates that some assumptions be made about the water lost from each fuel at each stage of combustion. It is also necessary to assign a net endotherm for this water loss.

As to the endotherm, it was assumed that water driven off during flaming was lost as the vapor at $1000^{\circ} \mathrm{C}$ and consumed $4.45 \mathrm{MJ} / \mathrm{kg}$; this accounts for the sensible enthalpy and heat of vaporization starting from liquid water at $25^{\circ} \mathrm{C}$. Water driven off during smoldering was assumed to be lost as the vapor at 500 ${ }^{\circ} \mathrm{C}$, consuming $3.4 \mathrm{MJ} / \mathrm{kg}$. A mass weighted average of these values together with the dry fuel heats of combustion was used to obtain an estimate of the net heats of combustion.

For the slash the assignment of net water loss during flaming depended on the fuel diameter. Water is driven out as heat penetrates the cylindrical fuel by conduction. As a first approximation this thermal wave penetrates to a depth proportional to the square root of the thermal diffusivity times the time of heat exposure. This ignores the not insignificant thermal effects due to water 
vaporization. Reference 10 shows that when water vaporization is ignored the center of a cylinder will reach one half of the surface temperature when

$$
\left(\alpha t / r^{2}\right)=0.2
$$

where $\alpha$ is the thermal diffusivity of the wood, $t$ is the time of heat exposure and $r$ is the radius of the cylinder. Since the surface temperature achieved on the wood surface during burning is $600-700^{\circ} \mathrm{C}$, satisfying this criterion should provide an extra quantity of heat that partially accounts for the water vaporization endotherm. Applying this criterion as a function of the wood cylinder radius, using a value for wood diffusivity from Ref. 11, one finds the following:

\begin{tabular}{cr} 
Radius $(\mathrm{cm})$ & Time $(\mathrm{mi}$ \\
\hline 1 & 1.6 \\
2 & 6.3 \\
3 & 14.3 \\
4 & 25.4 \\
5 & 39.7
\end{tabular}

Here the indicated time is that needed for the cylinder center to reach $3 / 2$ the surface temperature. From this and a flaming time of three minutes, it is estimated that twigs smaller than $3 \mathrm{~cm}$ diameter lose all of their water content during flaming; large diameter boles ( $>7 \mathrm{~cm}$ dia.) lose only 5 of of their mass during flaming so it is assumed they lose virtually no water during this process. All twigs in the range 3 to $7 \mathrm{~cm}$ diameter are then assumed to have lost half of their water content during flaming. The accuracy of this is obviously difficult to assess but it appears to be a reasonable rule of thumb. In calculating the effective heat of flaming of the slash, these estimates of fractional water loss were combined with the Forestry Canada data on water content as a function of slash size (Table 4) to infer the size-dependent endotherm to be subtracted from the dry heat of flaming combustion.

Smoldering of the slash lasts substantially longer than the flaming phase (recall Forestry Canada's estimates of $3 \mathrm{~min}$. for flaming and 22 min. for smoldering). There is thus a more substantial opportunity for water loss even though the driving temperatures are lower. It is assumed that the 3 to $7 \mathrm{~cm}$ diameter twigs lose their remaining water during smoldering. It is rather arbitrarily assumed that the largest slash material loses $\frac{1}{4}$ of its water content during smoldering. The dry heat for slash smoldering is corrected downward for water endothermicity in a manner analogous to that for flaming.

The water content of the litter/duff layer appears to increase linearly with depth below the surface (Table 4). Note that it becomes quite high. Sandberg [12] indicates that duff will not burn on its own unless the water content is below $30 \%$ (by weight of the dry fuel; this is $23 \%$ of the total weight). Recall that in our Cone Calorimeter measurements on the duff/litter mixture we got no flaming except with material that had only 7 \& (of total weight) as water. Evidently the duff layer requires a substantial degree of drying during the slash flaming interval if its observed weight loss (Table 2) is to be explained. 
In keeping with the Forestry Canada assumption that all of the leaf litter is consumed during flaming, we have assumed that all of its water content is also vaporized during this interval. The dry mass of this layer is reported to be $0.61 \mathrm{~kg} / \mathrm{m}^{2}$. Assuming that the water content of the duff/litter layer is linear with depth and using the data in Table 4 to infer this dependence, we calculate that the water in the leaf litter amounts to $0.22 \mathrm{~kg} / \mathrm{m}^{2}$.

This does not provide for any water loss from the duff below the leaf litter. From the Forestry Canada correlation for duff loading vs. duff depth [13]:

$$
\text { duff loading }\left(\mathrm{kg} / \mathrm{m}^{2}\right)=0.3759 \mathrm{x}^{1.6715}
$$

where $\mathrm{x}$ is the layer depth in $\mathrm{cm}$, we infer that the leaf litter was $1.3 \mathrm{~cm}$ deep. Table 2 shows that the average total decrease in litter/duff layer depth was $3.5 \mathrm{~cm}$. Using the above relation and the linearized water content with depth, we infer that the additional duff removed by smoldering contained 1.85 $\mathrm{kg} / \mathrm{m}^{2}$ of water. As an upper estimate, we assume that half of this was lost during the flaming litter phase; this is an upper estimate because the endothermicity of this water vaporization is comparable to the exothermicity of the leaf litter flaming. We infer that the true value must 1 ie between 0.22 and $0.92 \mathrm{~kg} / \mathrm{m}^{2}$; we have used the average of these two extremes in estimating the heat of flaming for the leaf litter and the heat of smoldering of the duff. The uncertainties in both of these numbers are thus substantial from this source alone (see below).

\section{5) CALCUlation of heAt RELEASE RATE}

As indicated above, there are certain ambiguities in the input data which cannot be resolved at this point. Therefore, we have undertaken the task of calculating the overall heat release rate in more than one way to see how sensitive the predicted flow field is to this calculation. The major impact of these differing modes of calculation is on both the total rate of heat release at a given time and on the spatial distribution of this release. Both of these can be expected to have some impact on the calculated flow field. While these differing calculations can shed some light on the interaction of the flow field calculation with the heat release pattern, they cannot be said to bracket the full range of possibilities. As indicated above in several places, there are uncertainties in some of the inputs for which we presently have no estimate; thus we cannot bracket the extremes of possible heat release patterns for this fire.

Block Al. The heat release pattern in this Block is needed because it was ignited first and it is close enough to Block A to create significant winds there during the time period of interest. No mass loss data were collected on Block Al but Forestry Canada has judged the fuel characteristics there to be sufficiently similar to those of Block A that Block A data should apply.

Because Block Al burn area data are sketchy, as noted above (Fig. 1) and because this area is, for the most part, somewhat removed from the region in Block $A$ of greatest interest, we have not attempted to calculate the Block $\mathrm{Al}$ heat release with the same level of effort as was applied to Block A. Block Al 
was broken into three segments and each segment was assigned a single ignition time, approximately that midway through the ignition of that segment. Figure 5 shows the three segments. Their borders are approximate, having been inferred from the IR tape where ground features are quite hard to discern. The assigned areas and times are as follows:

\section{Segment $\quad$ Fraction of Total Al Area}

1

2

3
$2 / 3$
$1 / 6$
$1 / 6$
Ignition Time

$$
\begin{aligned}
& 13: 52 \\
& 13: 55 \\
& 14: 07
\end{aligned}
$$

The shapes of these areas were simplified even further to rectangles when the flow field calculations were done.

For each segment of $\mathrm{Al}$ the rate of heat release was estimated by two different models. In the first model we utilize the simplest assumptions: ( 1 ) flaming is confined to a characteristic flaming time; it is followed by smoldering with its own characteristic time; (2) during both of these intervals the mass loss and thus the heat release rates are constant. We have used the Forestry Canada times for both of these combustion intervals (3.2 min. for flaming; $22.1 \mathrm{~min}$. for smoldering twigs; $30 \mathrm{~min}$. for smoldering duff). Since we are only interested in Block Al at times of 14:19 or greater, there is no flaming persisting in any of the segments, according to this model, even if the spread of flames takes several minutes after the completion of the ignition pattern. The calculated heat release rates per unit area for all combustion processes are reported here; the flaming values are used later in Block $A$.

\section{Heat Source}

Flaming twigs/boles Flaming leaf litter Smoldering twigs/boles Smoldering duff

\section{Average Heat Release Rate $\left(\mathrm{kW} / \mathrm{m}^{2}-2\right.$}

$16^{53}-38$
126
$7.7-9.5$

The water vaporization has been included in all of these estimates; the uncertainty in the amount vaporized is the source of the spread for the leaf litter and the duff; ultimately the average values were used in these cases. Note the unexpected dominance of the smoldering woody material as the largest heat source. This is due not only to the fact that the largest heat of combustion was used for this process (Table 6); it is also very much a consequence of the large mass of wood which is alleged to disappear by smoldering in 22 minutes. In the Cone Calorimeter measurements on the twig samples, the rate of heat release during smoldering was about a factor of five less than the peak value during flaming. Thus the result above appears improbable and prompts an alternative description below.

Table 7 shows the calculated heat release rate behavior for Block Al under the assumptions in this model. The time is broken into the intervals shown because of the need to keep track of the two different smoldering processes in each of 
the three segments. These results are used together with results (below) based on the same constant rate assumption for Block $\mathrm{A}$.

In the second model used to describe the rate of heat release in $B l o c k A l$, the constant rate assumption is replaced by an assumption of exponential decay, as suggested by Ref. 7. Strictly speaking there must be a build-up of mass loss rate in any newly ignited area as a consequence of spreading flames before the exponential decay sets in. It is estimated here that this build-up period is of the order of $7 \mathrm{~min}$. (based on Figure 1); a flaming period then follows with an assigned decay constant of 3 minutes. The decay of flaming thus begins in the last ignited segment (\#3) at 14:14; with a decay constant of 3 min. it is generating a negligible amount of heat (compared to smoldering) by the time of the earliest application of this model to a flow field calculation (14:22). Thus, for the present purposes, only smoldering occurs in Block Al, according to this simplified exponential decay model during the time when Block $A$ is the focus of interest.

Note that an exponential decay model implies a substantial reapportionment of the rate of heat release over time, compared to the constant rate model, if the same time constant is applied to both. The flaming time constant of 3 min. is sufficiently short (and uncertain) that it is probably adequate, in the context of this model, to justify the neglect of flaming during the time of interest. Adoption of the 22 and $30 \mathrm{~min}$. smoldering time constants as decay times for an exponential model would probably lead to results in conflict with the thermocouple measurements, however. We have adopted instead a single time constant of $16 \mathrm{~min}$. based on an approximate fit of an exponential decay law to the USFS mass loss rate results. This is rather rough but it is the only experimental basis for such a choice; we will consider one further possibility below, but only in the context of Block $A$.

With this model we thus have the following contributions to Block Al heat release in each of the three segments in the time interval of interest.

$$
\begin{array}{llll}
\text { Smoldering twigs/boles: } & \left.\mathrm{Q}_{\mathrm{ST}}=174 \exp \left[-\left(t-t_{\mathrm{ign}}\right) / 16\right)\right] & \left(\mathrm{kW} / \mathrm{m}^{2}\right) \\
\text { Smoldering duff: } & \left.\mathrm{Q}_{\mathrm{SD}}=16 \exp \left[-\left(t-t_{\mathrm{ign}}\right) / 16\right)\right] & \left(\mathrm{kW} / \mathrm{m}^{2}\right)
\end{array}
$$

Here $t_{i g n}$ is the ignition time for smoldering in each segment of Block Al; it is taken to be $10 \mathrm{~min}$. later than the flaming ignition times listed above. This comes from $7 \mathrm{~min}$. for flame spread followed by $3 \mathrm{~min}$. of flame decay before smoldering is assumed to begin; obviously it is a rather crude representation of the more complex real sequence of events. The total heat release in each segment is then obtained by multiplying the sum of the above expressions (with the appropriate ignition time) by the estimated area of that segment. The total heat release at $14: 22 \frac{1}{2}$, for example, is found to be $4.5 \cdot 10^{7} \mathrm{~kW}$ by this model; this is seen to be nearly a factor of two lower than the estimate in Table 7 for the constant rate model at the same time.

Block A. Three different models were used to estimate rate of heat release in Block A (instrumented area). The first was identical to the constant rate model used for Block Al. The results are summarized in Table 8; they have been calculated only for those times, at approximate $3 \mathrm{~min}$. intervals, at which 
relatively good results were available for the shape of the burn area in Block A. These shapes are a crucial element in apportioning and positioning the heat release rate in the flow field calculations of Section 6 . Note that it is now necessary to distinguish flaming and smoldering areas. As noted above, this is done on the assumption that only the new burn area generated in the last characteristic flaming time interval is flaming; the remaining area is smoldering. The flaming time interval used here is 3 minutes. Note that around 14:27 the total rate of heat release in Block A matches then exceeds that in Block Al, according to this model.

The second model for heat release rate in Block $A$ is a refined version of the exponential model used in Block Al. The refinement accounts for the fact that each new area segment was ignited as a continuous function of time and not at some fixed time (estimated for Block $A l$ as the middle of the ignition interval). At each local position the heat release rate due to flaming or smoldering is again taken to be decaying exponentially. However we now integrate over the range of ignition times in the flaming interval. Consider the mass loss process (which is proportional to the heat release rate). At a time, $t$, the mass loss rate via a single combustion process in an area where that process is being continually spread as a result of ignition and combustion spread processes is given by:

$$
M(t)=\int_{0}^{t}\left(d A / d t^{\prime}\right) \cdot m\left(t-t^{\prime}\right) \cdot d t^{\prime} \quad(\mathrm{kg} / \mathrm{min})
$$

Here $\left(d A / d t^{\prime}\right)$ is the rate at which new area is getting involved in this combustion process and $m\left(t-t^{\prime}\right)$ is the mass loss rate per unit area of an area element which begins to lose mass at time $t^{\prime}$, in the interval from 0 to $t$. The integration is over all values of start time of the process up to the time of interest. Here it is assumed that ( $\left.\mathrm{dA} / \mathrm{dt}^{\prime}\right)$ can be approximated as constant in the short ( 3 min.) intervals to which this will be applied. The local mass loss rate per unit area is taken to be exponential in character, as noted, so:

$$
\left.m\left(t-t^{\prime}\right)=a \cdot \exp \left[-\left(t-t^{\prime}\right) / \mathrm{b}\right)\right] \quad\left(\mathrm{kg} / \mathrm{m}^{2} \cdot \mathrm{min} .\right)
$$

Here $b$ is the decay time for the combustion process and the value of the preexponential factor, $a$, is obtained from an overall mass conservation statement for the given combustion process. Combining the above two equations and integrating, one finds:

$$
M(t)=b \cdot(\Delta A / \Delta t) \cdot a \cdot[1-\exp (-t / b)]
$$

where here the value assigned to $(\Delta A / \Delta t$ ) is the new burn area (from the IR tape results) generated in the characteristic flaming time ( $\Delta t=t_{F}$, which is taken to be 3 minutes), divided by the value of that characteristic time. This expression applies to an area where the combustion process has been spreading in the last $t_{F}$ minutes; thus it applies to flaming (twigs/boles and leaf litter) in the new burn area generated in the last $t_{F}$ minutes but it also applies to smoldering (twigs/boles or duff) in the area generated between $t_{F}$ and $2 \cdot t_{F}$ minutes ago (with appropriate values of $a, b$ and $\Delta A / \Delta t$ ). Smoldering is treated here as though it spreads behind the flame front with a time lag of $t_{F}$ 
minutes. The heat release rate from any of these processes in such areas of newly ignited flames or smoldering is obtained by multiplying the above expression (Eq. 1 with the $b$ and a values appropriate to each process) by the heat of combustion for that process (with water vaporization factored in, as discussed above).

After an area increment has been fully ignited into a flaming or smoldering mode, it is still necessary to account for the fact that successive portions of that area were ignited at differing times. Thus the mass loss rate from any particular combustion process is given by:

$$
\left.M(t)=\int_{0}^{A} a \cdot \exp \left[-\left(t-t_{i g n}\right) / b\right)\right] \cdot d A^{\prime}
$$

where $A$ is the area increment generated in the characteristic flaming time; a and $b$ are again generic values for the pre-exponential constant and decay time for the particular combustion mode and fuel type under consideration. By analogy to the assumption above that burn area in a short time interval can be taken to increase linearly with time, one has:

$$
t_{i g n}=\left(t_{E} / A\right) \cdot A^{\prime}
$$

Inserting this and integrating, one finds:

$$
M(t)=a \cdot b \cdot(\Delta A / \Delta t) \cdot\left[\exp \left(t_{F} / b\right)-1\right] \cdot \exp (-t / b)
$$

where, as before $(\Delta \mathrm{A} / \Delta t)$ is evaluated as the new burn area added in $t_{F}$ minutes during the absolute time interval pertinent to the burn area being considered. Again one obtains the rate of heat release from each flaming or smoldering process by multiplying Eq. (2) by the net reaction heat pertinent to that process.

Eq. (1) applies only to newly ignited areas (flaming or smoldering); Eq. (2) applies to all the subsequent history of each area increment. In applying these, it is necessary to keep careful track of the time history of each area increment under consideration.

Note that now it is necessary to add flaming and smoldering heat release components to all area increments except that which was ignited to flaming in the last $t_{F}$ minutes. The assumption of exponential decay means that the heat release process in all areas due to all processes lasts indefinitely long, though, of course, the heat from fast decaying processes may well become negligible compared to slowly decaying processes after a short period of time. The exponential decay assumption merely re-allocates the heat release rate with respect to time; it can be shown by integrating Eq. (1) and (2) from zero to infinity that the same total mass is being lost from any given area as was the case with the constant mass loss rate assumption. A result of this reallocation with respect to time is a re-shaping of the spatial distribution of heat release rate at any given time. 
The preceding expressions yield the following equations that were actually used to calculate rate of heat release. The heat of combustion values are the same as those used in Block Al, discussed above.

Most recent area ignited to flaming:

$$
\operatorname{RHR}_{F}(t)=53.5 \cdot\left[A(t)-A\left(t-t_{F}\right)\right]
$$

This is a simpler, reduced form of Eq. (1) because for flaming $b$ equals $t_{F}$ and the relative time at which this expression is evaluated for a newly flaming area is $t_{F}$. This includes the heat contributions from both flaming twigs/boles and leaf litter.

The next area increment, which was ignited to flaming $t_{F}$ minutes before the one above, has decaying flames and newly "ignited" smoldering. For the decaying flames:

$$
\operatorname{RHR}_{F}(t)=146 \cdot\left[A\left(t-t_{F}\right)-A\left(t-2 \cdot t_{F}\right)\right] \cdot \exp (-t / 3)
$$

The time relevant to the exponential is the time since combustion in this area was first begun.

For the new smoldering:

$$
\operatorname{RHR}_{S}(t)=1013 \cdot\left[A\left(t-t_{F}\right)-A\left(t-2 \cdot t_{F}\right)\right] \cdot(1-\exp [-(t-3) / 16]\}
$$

This is Eq. (1) applied to smoldering whose time constant, 16 min., is distinctly different from the $3 \mathrm{~min}$. time constant assumed for flaming; thus the expression is more complex than that for flaming in a newly ignited area. This includes the heat release from both smoldering twigs/boles and duff. The total heat release rate in this area increment is the sum of the flaming and smoldering contributions.

Finally, any area increment which contains both decaying flaming and decaying smoldering is described by expressions like the following (where one must keep track of the local time history and appropriate value of the area increment as this is applied to various area increments in succession).

For the decaying flames:

$$
\operatorname{RHR}_{F}(t)=146 \cdot\left[A\left(t-2 \cdot t_{F}\right)-A\left(t-3 \cdot t_{F}\right)\right] \cdot \exp (-t / 3)
$$

For the decaying smoldering:

$$
\operatorname{RHR}_{S}(t)=209 \cdot\left[A\left(t-2 \cdot t_{F}\right)-A\left(t-3 \cdot t_{F}\right)\right] \cdot \exp [-(t-3) / 16]
$$

Again the flaming and smoldering contributions are added together to get the total heat release rate for such an area increment.

These expressions have only been evaluated for four absolute times; the results are shown in Table 9. The changes in total heat release rate at the four times shown there are significant but not very great when compared to the constant 
mass loss rate model at the same times (Table 8). At larger times in the same areas, the differences will ultimately become much larger. In the constant rate model, $33 \mathrm{~min}$. after flaming starts all combustion ceases in a given area segment. In an exponential decay model all combustion processes persist indefinitely at ever slower rates.

The third model applied to Block $A$ is a further refinement of the exponential model just described. The refinement addresses the point noted more than once above regarding the large amount of woody bole mass assigned to the smoldering mass loss category with the same time constant as was applied to the twigs. This author does not find it credible that large masses of large diameter boles can be consumed by smoldering in a short time period. Recall that the Forestry Canada slash statistics (Table 1) indicate that $6.6 \mathrm{~kg} / \mathrm{m}^{2}$ of the average total slash mass loss of $7.5 \mathrm{~kg} / \mathrm{m}^{2}$ is due to smoldering; 768 of this smoldering loss is in the $>7 \mathrm{~cm}$ diameter size class. In this author's experience with the smoldering of solid wood [14], it is a very slow process which takes many hours, being limited by the rate of air supply. If the rate of air supply is boosted by an air flow the smoldering transitions to flaming, which, of course, yields more rapid consumption.

The behavior of the large wood boles has not been specifically monitored in this experiment. The thermocouples used by both Forestry Canada and by NIST were not placed in any definite relationship to these boles. Thus it is doubtful that the thermocouple results have any real bearing on what these boles were doing during the burn. The video tapes from inside the fire showed that some of the closely packed, large diameter boles continued to flame for time periods of twenty minutes or more. What fraction of the boles did this cannot be estimated from the available data.

In view of the uncertainty here with regard to the behavior of the large boles, we have explored the impact of assuming different behavior for this segment of the fuel load. Thus the same time constants as were used above for flaming and smoldering are applied again here to all but the $>7 \mathrm{~cm}$ dia. boles. For these large fuel elements, however, we have chosen time constants of 15 min. for flaming and $60 \mathrm{~min}$. for smoldering. These chosen values are actually rather short for fixed fuel elements undergoing either flaming or smoldering; sizedependent fuel bed collapse could shorten either of these combustion modes in the field, however. These relatively short values are also something of a concession to the fact that long values are not in keeping with the USFS mass loss rate curve. This situation is clearly not satisfactory; future work in this area should resolve the actual behavior of large boles of wood.

To implement this model it is necessary to keep separate track of heat release from slash below and above $7 \mathrm{~cm}$ diameter. Otherwise the model is the same as the exponential model described above. Thus one has in an area newly ignited to flaming:

$$
\begin{aligned}
& \operatorname{RHR}_{E<7}(t)=41.1 \cdot\left[A(t)-A\left(t-t_{F}\right)\right] \\
& \operatorname{RHR}_{F>7}(t)=3.6 \cdot\left[A(t)-A\left(t-t_{F}\right)\right]
\end{aligned}
$$

These are added together to obtain the total heat release in this area. 
In the adjacent area increment where both decaying flaming and newly "ignited" smoldering are occurring:

$$
\begin{aligned}
& \operatorname{RHR}_{F<7}(t)=112 \cdot\left[A\left(t-t_{F}\right)-A\left(t-2 \cdot t_{F}\right)\right] \cdot \exp (-t / 3) \\
& \operatorname{RHR}_{F>7}(t)=4.4 \cdot\left[A\left(t-t_{F}\right)-A\left(t-2 \cdot t_{F}\right)\right] \cdot \exp (-t / 15) \\
\operatorname{RHR}_{S<7}(t)= & 312 \cdot\left[A\left(t-t_{F}\right)-A\left(t-2 \cdot t_{F}\right)\right] \cdot\left(1-\exp \left[-\left(t-t_{F}\right) / 16\right]\right) \\
\operatorname{RHR}_{S>7}(t)= & 702 \cdot\left[A\left(t-t_{F}\right)-A\left(t-2 \cdot t_{F}\right)\right] \cdot\left\{1-\exp \left(-\left(t-t_{F}\right) / 60\right]\right)
\end{aligned}
$$

Again it is necessary to add all of these four contributions together to get the total rate of heat release in this area increment.

In the next area increment where both the flames and the smoldering are decaying (and analogously in all further increments of this type), the flames are described by the same two expressions as those given just above (with appropriate attention to utilization of the correct local time and area value). The smoldering is described by the following two expressions:

$$
\begin{aligned}
& \operatorname{RHR}_{S<7}(t)=64 \cdot 3 \cdot\left[A\left(t-2 \cdot t_{F}\right)-A\left(t-3 \cdot t_{F}\right)\right] \cdot \exp \left[-\left(t-t_{F}\right) / 16\right] \\
& \operatorname{RHR}_{S>7}(t)=36.0 \cdot\left[A\left(t-2 \cdot t_{F}\right)-A\left(t-3 \cdot t_{F}\right)\right] \cdot \exp \left[-\left(t-t_{F}\right) / 60\right]
\end{aligned}
$$

The flaming and smoldering heats are added together to get the total for such increments.

Once again these expressions have only been evaluated for four absolute times, the same as were used for the simple exponential model described above. The results for these four times are shown in Table 10. Comparing these to the results for the simple exponential model in Table 9, one sees that the changes (in a given area increment) in the flaming heat release rate are fairly minor; the changes in smoldering heat release rate are about a factor of two. Figure 6 shows the total heat release rate for the three models as a function of time. As the rate of new flaming area accumulation slows at later times (see Fig. 2), the relative contribution of flaming heat release decreases; as a result, the difference between the two models approaches the factor of two difference in the smoldering heat release rates.

It is worth re-stating that the above three models are not likely to have bracketed the extremes of possible values for the rate of heat release in Block A. Various uncertainties were noted in the previous discussion which could not be quantified. Thus we cannot say with any real assurance that the true values of total heat release rate are those found from any of the model curves in Fig. 6. The last model reduces the smoldering rate of heat release relative to the flaming rate but the former still dominates, contrary to expectation. These models do demonstrate that relatively large changes in the model parameters are needed to yield substantial changes in the overall heat release rate and in the distribution among various processes. 
Some of the rate of heat release results reported above have been used in an effort to calculate the near-ground flow field that they produce. The predictions are compared with the velocity vectors measured at specific sites in Block A (the instrumented block). The measured values come from Forestry Canada cup anemometers ten meters above the ground and are believed to have good accuracy ( \pm few percent) up to the time the fire reached their location. The velocity and wind direction data were noisy due to turbulence and thus were averaged over a three minute interval around the time of use. Since the ground in Block $A$ had height variations of the order of $\pm 15 \mathrm{~m}$, the ambient wind varied from point to point; this was accounted for by using local fifteen minute averages of the pre-fire wind to estimate an ambient wind vector during the fire.

The flow model used is that due to Baum and McCaffrey [1]. This model treats the fire as a collection of individual, radially symmetric fires which are to be placed spatially in accord with the burn patterns obtained from the infrared video tape. Applying this model here is not as simple as it sounds, however. There are two principal areas of complexity, quite apart from the questions as to the accuracy of the rate of heat release data. First, the model is sensitive to the actual number of individual fire plumes. The greater this number, the greater the net induced flow velocity because the total entrainment by the plumes increases. However, the infrared camera data discussed above do not provide clear-cut information on the number of plumes above any given burning area. Comparisons between visible photos and the infrared tape suggest that individual burning areas on the periphery of the fire yield distinct plumes but that, as one proceeds toward the center of the fire, plumes from more than one area rapidly merge to become one effective plume. The lack of any way to quantify this means the number of plumes assigned to Block $A$ at any given time is an estimate with an uncertain accuracy.

The second area of complexity in applying the flow model to this situation derives from the fact that Block Al was ignited first. It was pointed out above that this Block is effectively undergoing only smoldering combustion in the time interval of interest here for Block $A$ (the instrumented block). Estimates were made of the rate of heat release from this smoldering and it was noted that Block Al apparently dominates over Block A until 14:25 or later. Unfortunately, this is the time interval when the model comparison is to be made. The induced flow from Block Al must be part of the flow field calculation, therefore. However, the Baum and McCaffrey model is based on the structure of a flaming fire plume. There is no comparable information available for the structure of a plume over a smoldering area, particularly an area like that which Block Al presents in this time interval -- a 60 hectare fuel bed that is smoldering with an unknown degree of spatial uniformity. Application of the Baum and McCaffrey model to Block Al is thus an uncertain exercise, at best.

To deal with this second complication, the description of Block AI was adjusted, in the time before the Block $A$ heat release rate was significant, in an attempt to obtain the experimentally measured velocities at the anemometer positions. The ambient wind field tends to dominate and obscure the Block Al 
fire effects at most of these locations; the ambient wind was added vectorially to the velocity values predicted by the model. The added values were the average values computed at each anemometer position for the fifteen minutes prior to the start of ignition in Block Al. Adjustment of the Block Al description called for modifying the number and strength of the flaming plumelike fires assigned to the three segments of this Block within the constraint that each segment have the total energy release rate computed for it above. The actual locations of these fires within the confines of each segment of Block Al were randomly assigned.

The adjusting of the Al description was done at a time of 14:19. The heat release in Block $A$ (instrumented area) was two orders of magnitude less than that in Block Al (first block ignited). Figure 7 ( $a, b, c)$ shows the results of successive descriptions of the Block Al heat release distribution. Note that the heat release rate values used for all times here are those computed from the simple exponential decay model described above (Table 9 plus the appropriate exponential decay equations for Block Al). Note also that the description of the shape of Block Al has been approximated by a series of rectangles. The small area ignited in Block $A$ at this time is visible in this scaled diagram as a ring of small circles; see Fig. 3 for the placement of this ring relative to the anemometers. Each circle's fraction of the total circle area is proportional to the fraction it represents of the total Block $A$ heat release rate at this time. The letters designating the various velocity vectors are those assigned to the Forestry Canada anemometers. The line having half an arrow head at each anemometer location is the wind vector calculated from the model; the other line at each point is the measured wind vector at 14:19:20. Examination of Figure 7 reveals that the best agreement between model and experiment was obtained by having only five fires in Block Al (all three cases shown in Fig. 7 have the same total heat release rate); as the number of fires was increased the predicted magnitudes of the velocity vectors tended to become substantially larger than the measured values. This best description of Block Al was then retained for the model calculations at two further times; the total heat release rate in $A l$ was allowed to decay in accord with the calculations above.

As the fire grows in Block A, the proper description of it for the model is problematical, as indicated above. Initially this fire was described by a large number of small circular fires located so as to give very close conformance to the actual fire outline. This emphasis on fire shape ignored the fact that the model predicts increasing total entrainment as the number of fires increases (for the same value of total heat release rate); the resulting values of predicted wind velocity were much too high. Subsequently the total number of fires was reduced in accord with the indication, mentioned above, that the plumes appear to merge as one moves toward the center of the Block A fire. This resulted in a factor of four reduction in the number of plumes with some compromise as to the exact placement of the center of each plume relative to the real fire. (The coordinates of each plume are measured on a scaled map so that their position relative to the anemometers and to Block Al can be correctly determined.)

Figures 8 and 9 show the heat release patterns inserted into the model at 14:22:24 and 14:25:05, respectively. The pattern at 14:22 involved a fairly 
accurate assignment of a reduced number of fire plumes to the pattern revealed in the infrared video tape at this time; the pattern at 14:25 was deduced in a somewhat cruder fashion by lumping together successive groups of four fires from a spatially accurate description with a large number of fires.

Examination of these two Figures shows that the model does a fairly good job of predicting the magnitude of the velocity vectors; only location $C$ is off by a factor of two by $14: 25$. The model also seems to overestimate the shift in velocity vector orientation. Both the over-prediction of velocity magnitude and velocity orientation shift may be due, at least in part, to the fact that the model is steady state, as employed here. The overall fire in Block $A$ is growing very rapidly and the flow field may require a few minutes to adjust; thus the actual flow field would lag the steady flow field accompanying any given pattern of heat release by a few minutes. Of course the ambiguities, mentioned above, in applying this model to this difficult situation may also be at the heart of what appears to be an increasing difference between model an experiment as time progresses. Unfortunately, there were insufficient resources to pursue this comparison further.

\section{7) CONCLUDING REMARKS}

Accurate estimation of the overall rate of heat release from a large scale fire is a very challenging undertaking. While estimates have been produced here which fall in a fairly narrow band (factor of two), the true uncertainty in these values cannot presently be determined. It is clear that certain changes in the data collected could enhance the accuracy of the heat release estimate. Measurement of the water content of the fuels after the fire would eliminate this source of uncertainty. Use of an infrared camera with a logarithmic, rather than linear, pre-amplifier or the use of an attenuation filter placed before the lens at intervals would facilitate separation of flaming and smoldering areas. Finally, it would be desirable to instrument the spectrum of fuel bed types (differing packing densities, fuel types and diameters) in the burn area to obtain a better estimate of what must really be a spectrum of flaming and smoldering times. This last is non-trivial and probably calls for a research program of its own to define the best manner in which it could be implemented. Thus, while it is relatively easy in retrospect to suggest improved ways to obtain data for heat release rate estimates, it is another matter to implement them.

While the comparisons here between predicted and measured flow velocities are moderately successful, it is clear that a really critical test of the model was not possible in the context of this experiment. In fact, this type of experiment (prescribed forest burn) is ill-suited to testing this model. Even if Block $A l$ had not been ignited first, there would remain the major uncertainties of how to estimate the number of fire plumes driving the flow and how to handle the smoldering portion of the fuel bed that results from the relatively slow ignition process. In addition there is the unknown influence of the uneven terrain which the model does not include and, of course, the very considerable uncertainties in estimating the rate of heat release. A scaled down version of a Project Flambeau fire [16] or a well-defined set of liquid 
pool fires would be a much better context for testing the flow model of Baum and McCaffrey.

\section{ACKNOWLEDGEMENTS}

The authors would like to acknowledge helpful discussions with Howard Baum regarding the flow field calculations. William Rinkinen and Darren Lowe were extremely helpful in the field study aspects of this work. Ms. Robin Breese was a great deal of help in the post-test data reduction.

Forestry Canada personnel were extremely helpful throughout this project; the authors are particularly grateful to Doug McRae and Chuck Ogilvie. 
1) Baum, H. and McCaffrey, B., Fire Safety Science--Proceedings of the Second International Symposium, Hemisphere Publishing, Washington, D. C., 1989, pp. $129-148$

2) Brown, J., "Handbook for Inventorying Downed Woody Fuel", USDA Forest Service General Technical Report INT-16, 1974

3) McRae, D., The Forestry Chronicle, April, 1986, pp. 96-100

4) Brown, J., "Field Test of a Rate-of-Fire-Spread Model in Slash Fuels", USDA Forest Service Research Paper INT-116, 1972

5) Nelson, R., "An Evaluation of the Carbon Balance Technique for Estimating Emission Factors and Fuel Consumption in Forest Fires", USDA Forest Service Research Paper SE-231, 1981

6) McRae D. and Stocks, B., "Large Scale Convection Burning In Ontario", Ninth Conference on Fire and Forest Meteorology, April, 1987

7) Ward, D. and Hardy, C., "Advances in the Characterization and Control of Emissions from Prescribed Fires", Seventy-Seventh Annual Meeting of the Air Pollution Control Association, June, 1984

8) Susott, R., DeGroot,W. and Shafizadeh, F., J. Fire Flamm., 6, July, 1975 pp. $311-325$

9) Huggett, C., Fire Mater., 4, 1980, p. 61

10) Carslaw, H. and Jaeger, J., heat Conduction in Solids, Oxford University Press, London, 1959, p. 102

11) Parker, W., "Prediction of the Heat Release Rate of Wood", Ph. D. Thesis, George Washington University Department of Mechanical Engineering, April, 1988

12) Sandberg, D., "Duff Reduction by Prescribed Underburning in Douglas Fir", USDA Forest Service Research Paper PNW-272, June, 1980

13) McRae, D., Forestry Canada, private communication

14) Ohlemiller, T., "Products of Wood Smoldering and Their Relation to Wood Burning Stoves", National Bureau of Standards NBSIR 88-3767, May, 1988

15) McRae, D., Alexander, M. and Stocks, B., "Measurement and description of fuels and fire behavior on prescribed burns: a handbook", Department of the Environment, Canadian Forestry Service, Sault St. Marie, Ontario Informational Report 0-X-287 (1979)

16) Palmer, T. Y., "Large fire winds, gases and smoke", Atmospheric Environment, 15, No. 10/11, p. 2079 (1981) 


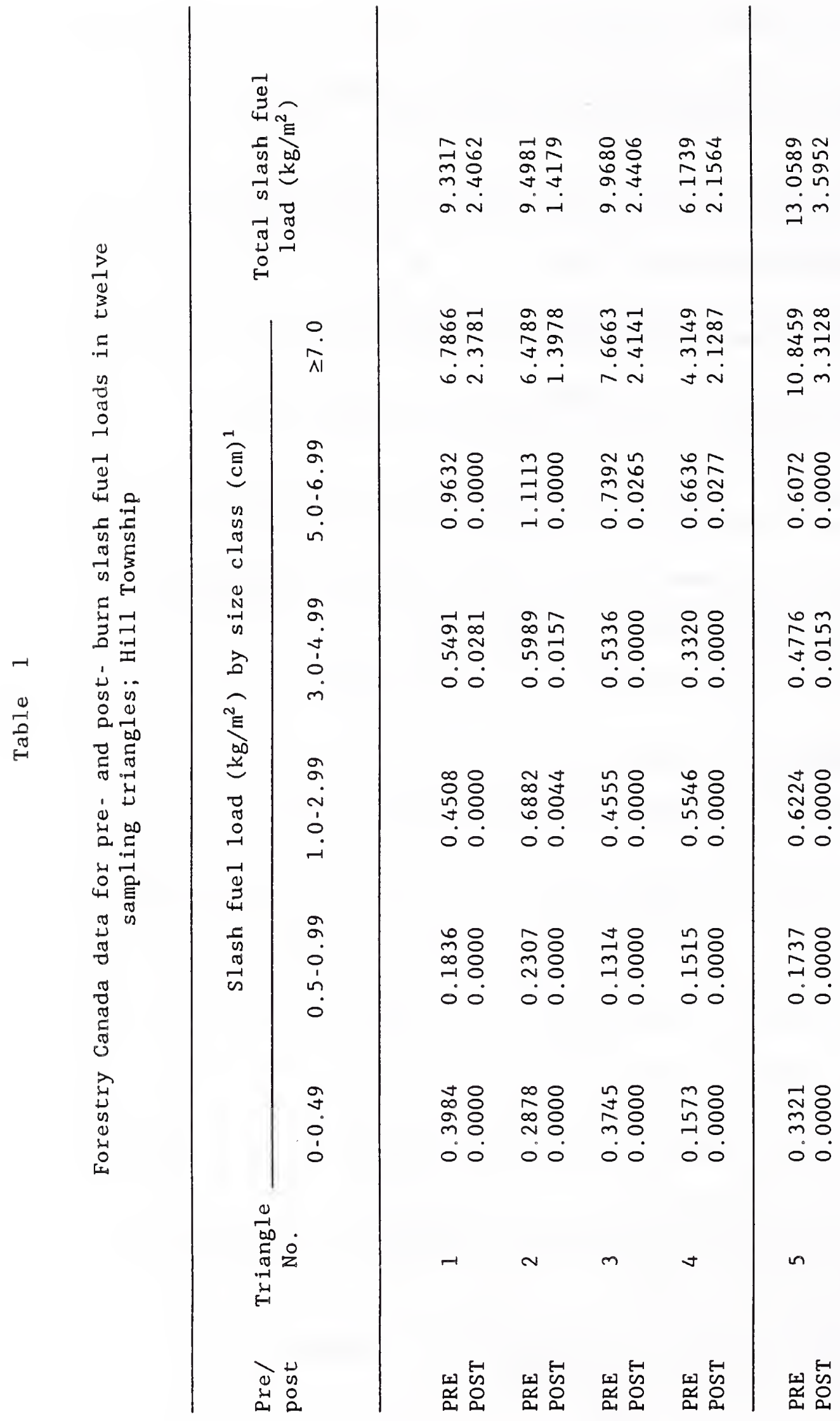




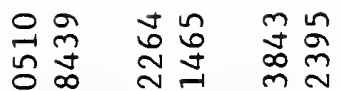

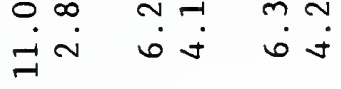

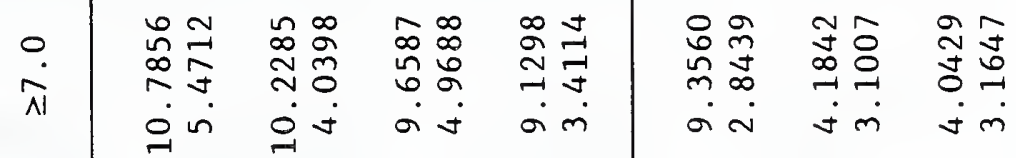

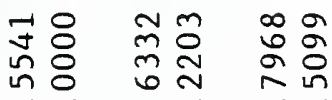
$\circ \dot{0} 0 \dot{0} 0$

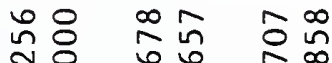
ษ $\circ \dot{0} 0 \dot{0} 0 \dot{0}$

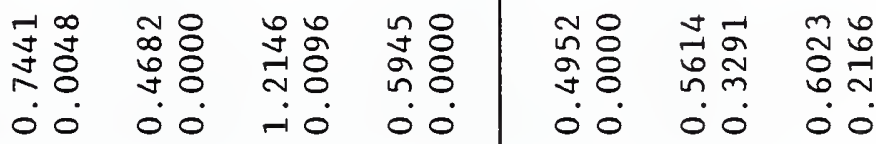

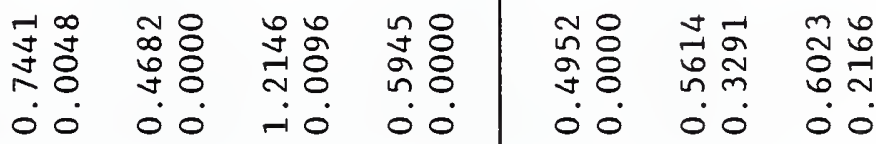

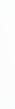

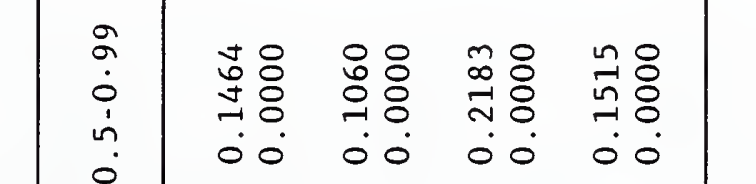

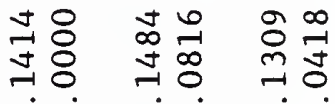

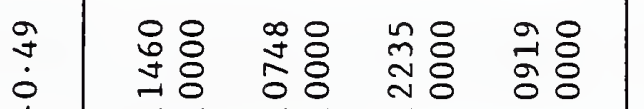

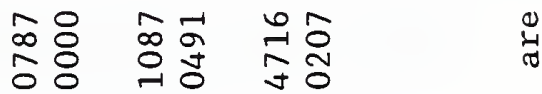
๙ู $\dot{0} \dot{0} \dot{0} 0 \dot{0}$

6

$r$

$\infty$

a

오

$\exists \quad$

$\sum_{4}^{01}$

$\frac{\pi}{\pi}$

受葍 
Table 2

Forestry Canada data for pre- and post burn duff loading in twelve sampling triangles; Hill Township

\begin{tabular}{|c|c|c|c|c|c|}
\hline $\begin{array}{l}\text { Eial } \\
\text { No }\end{array}$ & $\begin{array}{l}\text { Depth of } \\
\text { burn } \\
(\mathrm{cm})\end{array}$ & $\begin{array}{l}\text { Duff } \\
\text { remaining } \\
\text { (cm) }\end{array}$ & $\begin{array}{l}\text { Preburn } \\
\text { duff depth } \\
(\mathrm{cm})\end{array}$ & $\begin{array}{l}\text { Preburn } \\
\text { duff load } \\
\left(\mathrm{kg} / \mathrm{m}^{2}\right)\end{array}$ & $\begin{array}{c}\text { Duff } \\
\text { consumpt } \\
\left(\mathrm{kg} \backslash \mathrm{m}^{2}\right)\end{array}$ \\
\hline
\end{tabular}

$\begin{array}{rrrrrr}1 & 4.78 & 2.00 & 6.78 & 9.21 & 5.12 \\ 2 & 3.96 & 1.56 & 5.52 & 6.53 & 3.75 \\ 3 & 3.24 & 5.60 & 8.84 & 14.36 & 2.68 \\ 4 & 4.30 & 7.10 & 11.40 & 21.96 & 4.30\end{array}$

11

1.03

$20.0+$

$20.0+$

$14.16+$

0.54

12

0.42

$20.0+$

$20.0+$

$14.16+$

0.20

2.75

2.49

2.63

2.11

2.65

2.67

1) Duff Fuel loads were calculated using regression equations found in

Ref. 4-15. The duff type used was jack pine for all triangles except 11 and 12, in which, lowland black spruce was used.

2) Duff loads shown are dry fuel weight. 


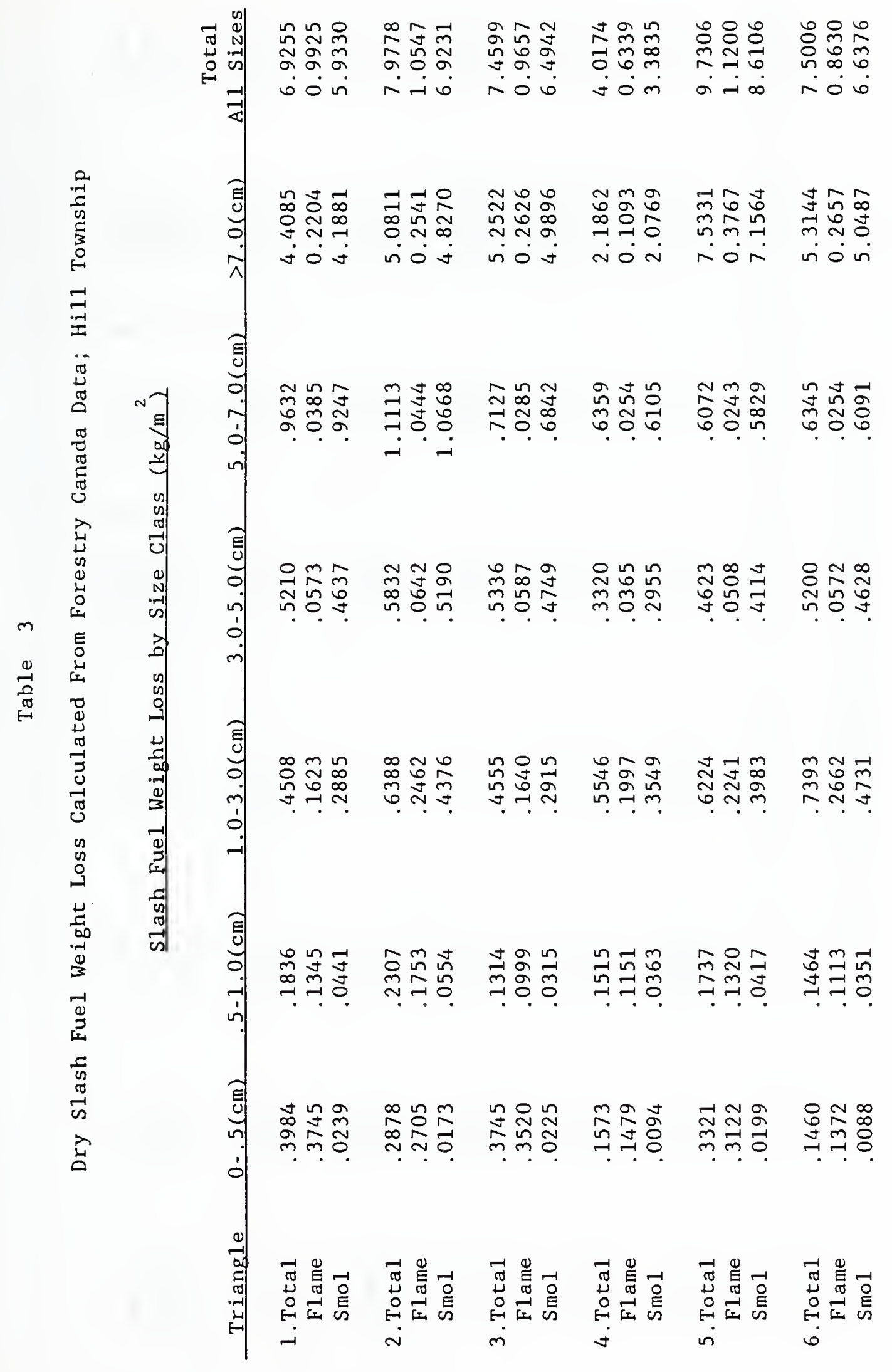




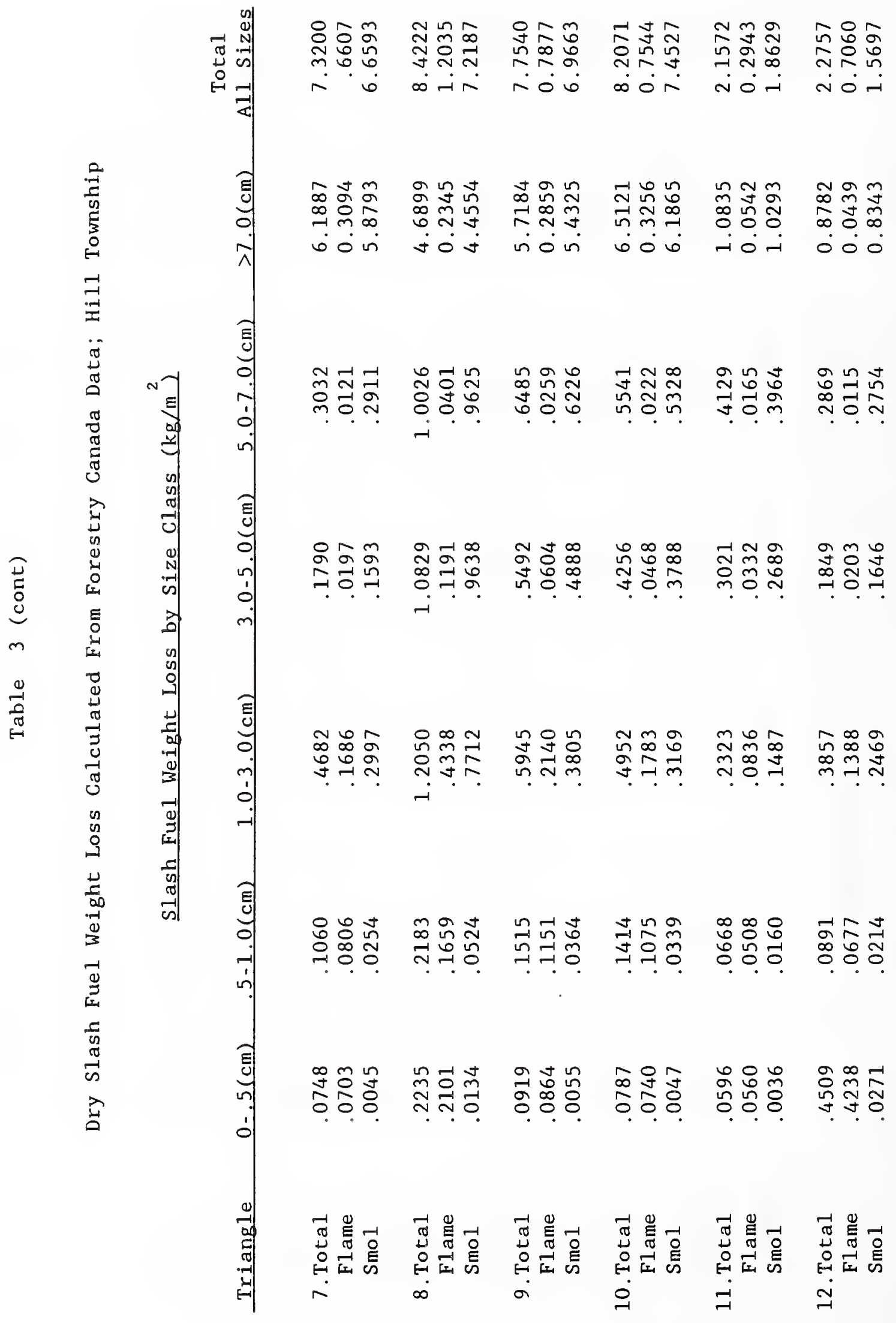


Table 4

Forestry Canada results for average oven - dry moisture content of various fuel classes; Hill Township

Fuel type

Fuel Moisture Content ( 8 )

Slash pieces $0.0 \cdot 0.49 \mathrm{~cm}$

23.3

Slash pieces $0.5-0.99 \mathrm{~cm}$

15.8

Slash pieces $1.0-2.99 \mathrm{~cm}$

25.2

Slash pieces $3.0-4.99 \mathrm{~cm}$

33.8

Slash pieces $5.0-6.99 \mathrm{~cm}$

33.2

Slash pieeces $\geq 7.0 \mathrm{~cm}$

38.0

Duff, top $0-2 \mathrm{~cm}$ layer

43.6

Duff, $2-4 \mathrm{~cm}$ layer

85.9

1 Expressed as weight percent of oven dry fuel weight 
Table 5

NIST Thermocouple Results

\begin{tabular}{|c|c|c|c|c|c|c|}
\hline Temp. $\left({ }^{\circ} \mathrm{C}\right)$ & Time Above & Temp & D. $(\mathrm{Sec})$ & $\begin{array}{r}\text { Tin } \\
\text { Drop To } 10 \\
\end{array}$ & $\begin{array}{l}{ }^{2} \\
{ }^{\circ} \mathrm{C}\end{array}$ & $\begin{array}{l}\text { To } \\
\text { (Sec) }\end{array}$ \\
\hline 300 & 544 & \pm & 569 & 888 & \pm & 950 \\
\hline 450 & 364 & \pm & 445 & & - & \\
\hline 600 & 211 & \pm & 168 & & - & \\
\hline 700 & 149 & \pm & 117 & 1499 & \pm & 1692 \\
\hline
\end{tabular}

1 From the thermocouples above the litter layer

2 From the thermocouples in the duff. This is the time, subsequent to the peak value, that it takes for the thermocouple to drop from the value in the first column down to $100^{\circ}$. 


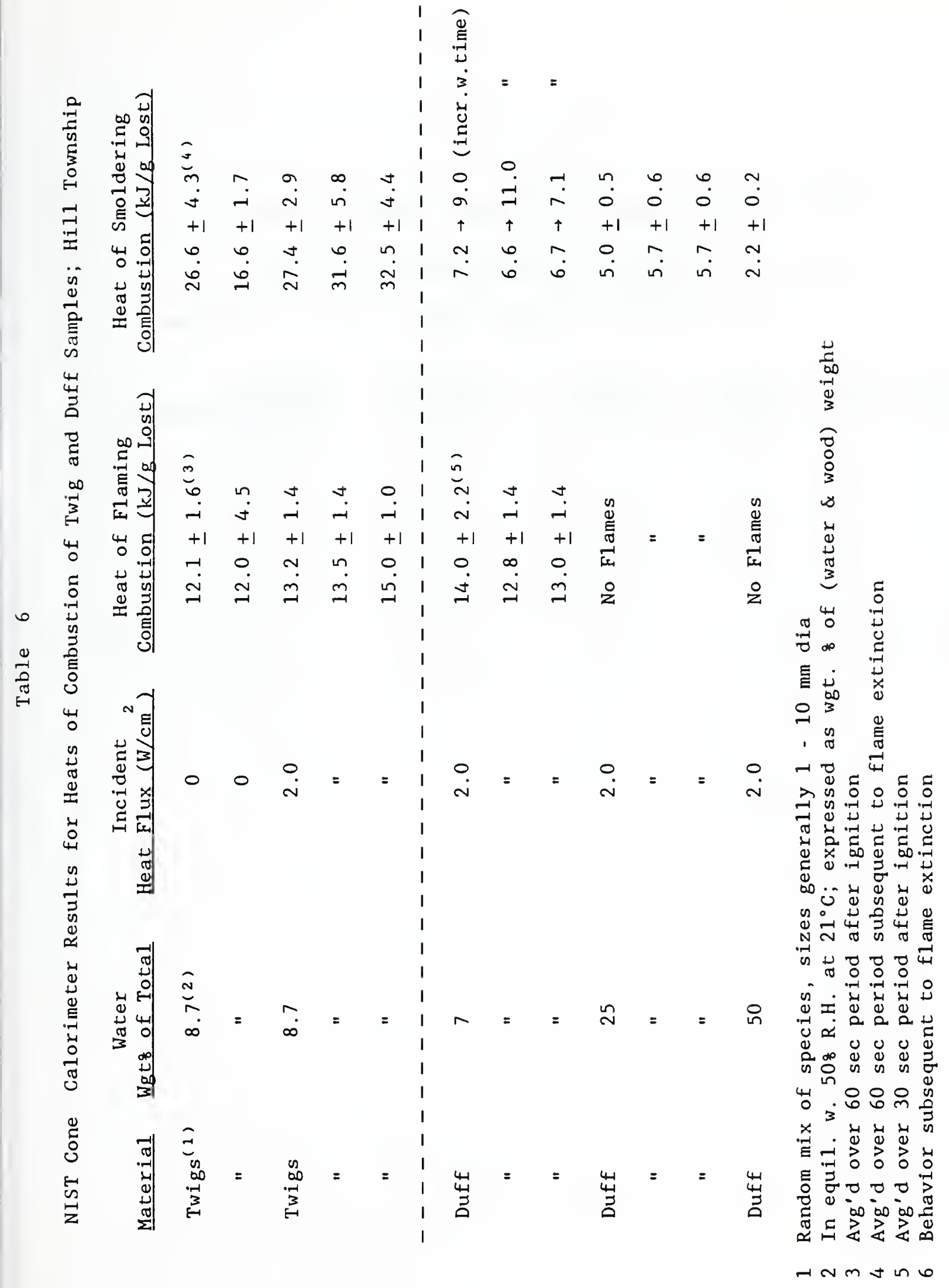




\title{
Table 7 \\ Block Al Heat Release Behavior For Model Utilizing \\ Constant Mass Loss Rates
}

\author{
Rate of Heat Release by Segment (kW)
}

$\begin{array}{ccccc}\text { Time Interval } & \text { Segment 1 } & \text { Segment 2 } & \text { Segment 3 } & \text { Tota1 RHR }(\mathrm{kW}) \\ 14: 19-14: 24 & 5.8 \cdot 10^{7} & 1.4 \cdot 10^{7} & 1.4 \cdot 10^{7} & 8.6 \cdot 10^{7} \\ 14: 24-14: 27 & 3.7 \cdot 10^{6} & 1.4 \cdot 10^{7} & 1.4 \cdot 10^{7} & 3.2 \cdot 10^{7} \\ 14: 27-14: 32 & 3.7 \cdot 10^{6} & 0.9 \cdot 10^{6} & 1.4 \cdot 10^{7} & 1.9 \cdot 10^{7} \\ 14: 32-14: 35 & 0 & 0.9 \cdot 10^{6} & 1.4 \cdot 10^{7} & 1.5 \cdot 10^{7} \\ 14: 35-14: 39 & 0 & 0 & 1.4 \cdot 10^{7} & 1.4 \cdot 10^{7} \\ 14: 39-14: 47 & 0 & 0 & 0.9 \cdot 10^{6} & 9.0 \cdot 10^{5} \\ 14: 47 & 0 & 0 & 0 & 0\end{array}$


Table 8

\section{Block A Rate of Heat Release Behavior for Constant \\ Mass Loss Rate Model}

\begin{tabular}{|c|c|c|c|c|c|}
\hline Time & $\begin{array}{l}\text { Flaming } \\
\text { Area }(\mathrm{m})\end{array}$ & $\begin{array}{c}\text { Smoldering } \\
\text { Area (m) }\end{array}$ & $\begin{array}{l}\text { Flaming } \\
\text { RHR (kW) }\end{array}$ & $\begin{array}{c}\text { Smoldering } \\
\text { RHR (kW) }\end{array}$ & $\begin{array}{l}\text { Total } \\
\text { RHR (kW) }\end{array}$ \\
\hline
\end{tabular}

$\begin{array}{llcccc}14: 19: 20 & \approx 3 \cdot 10^{3} & 0 & 2.4 \cdot 10^{5} & 0 & 2.4 \cdot 10^{5} \\ 14: 22: 24 & 5.6 \cdot 10^{4} & \simeq 3 \cdot 10^{3} & 4.2 \cdot 10^{6} & 4.0 \cdot 10^{5} & 4.6 \cdot 10^{6} \\ 14: 25: 05 & 6.1 \cdot 10^{4} & 5.9 \cdot 10^{4} & 4.9 \cdot 10^{6} & 8.0 \cdot 10^{6} & 1.3 \cdot 10^{7} \\ 14: 29: 21 & 8.0 \cdot 10^{4} & 1.5 \cdot 10^{5} & 6.4 \cdot 10^{6} & 2.0 \cdot 10^{7} & 2.6 \cdot 10^{7} \\ 14: 35: 35 & 4.0 \cdot 10^{4} & 2.9 \cdot 10^{5} & 3.2 \cdot 10^{6} & 3.9 \cdot 10^{7} & 4.2 \cdot 10^{7}\end{array}$


Table 9

\section{Block A Rate of Heat Release Behavior for a}

\section{Simple Exponential Decay Model}

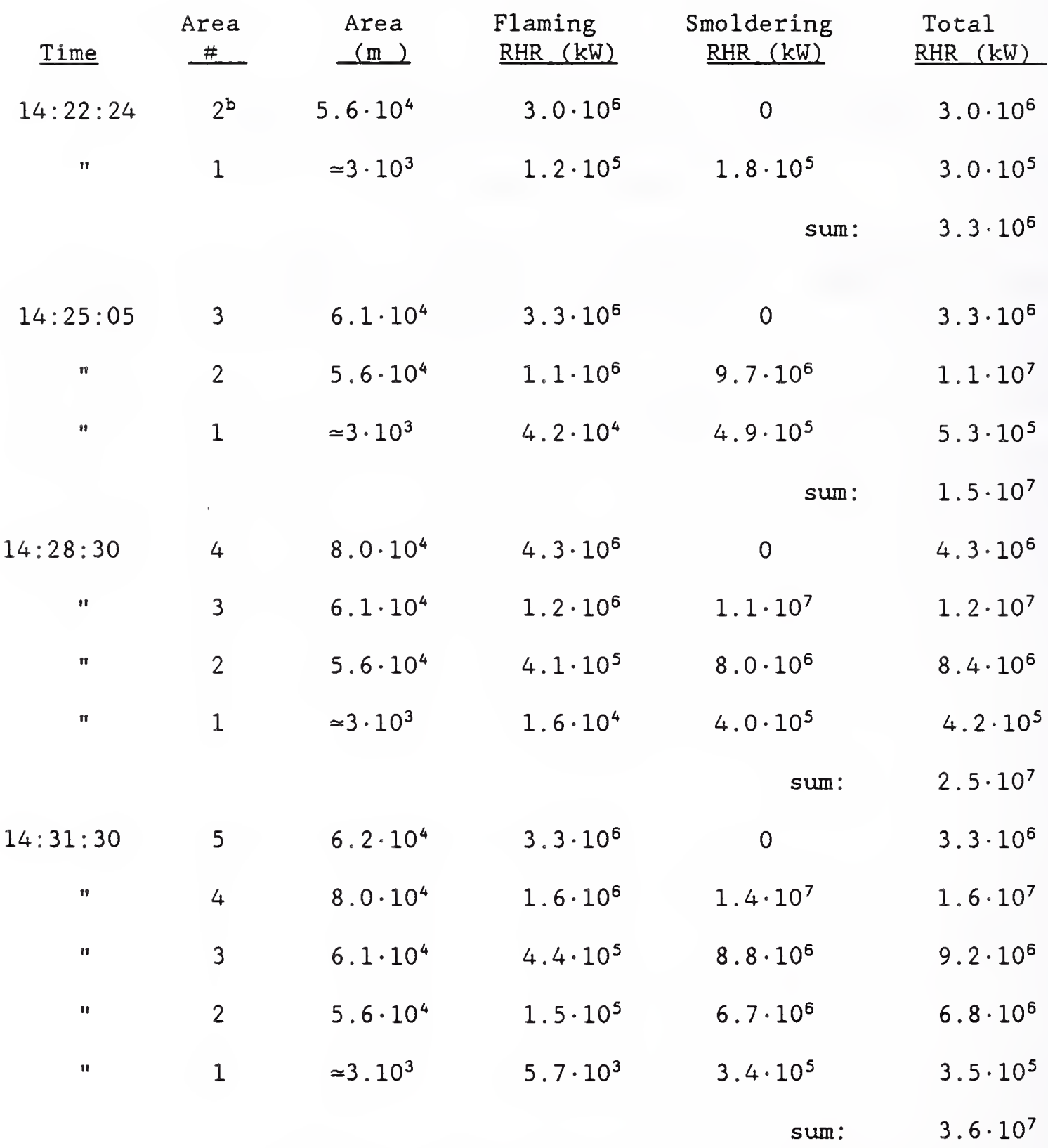

a) This is the total RHR in each area increment; the overall RHR at a given time is the sum shown for all area increments that are burning.

b) The area most recently ignited to flames is given the highest number here; the number for a specific area thus holds constant in this table. 


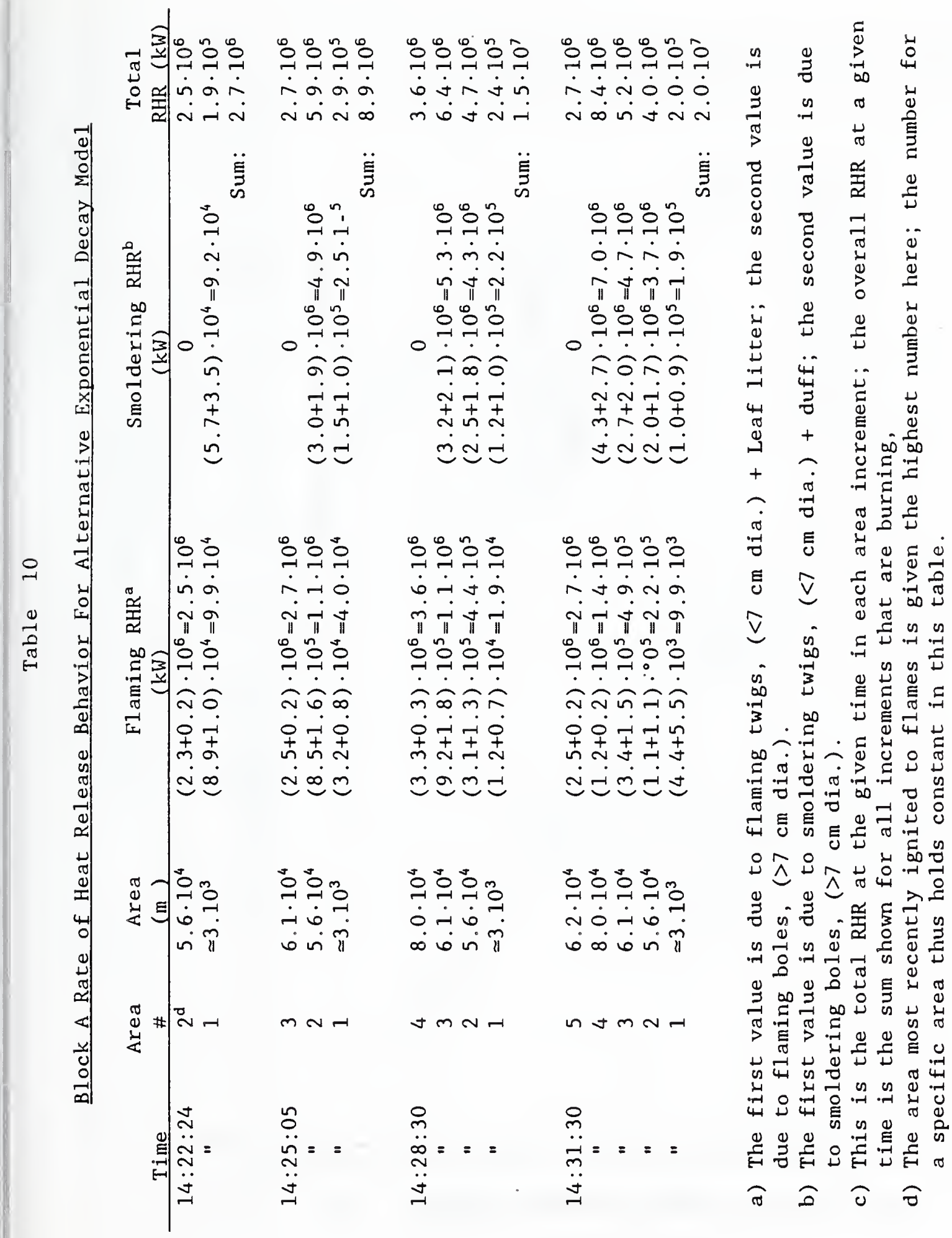




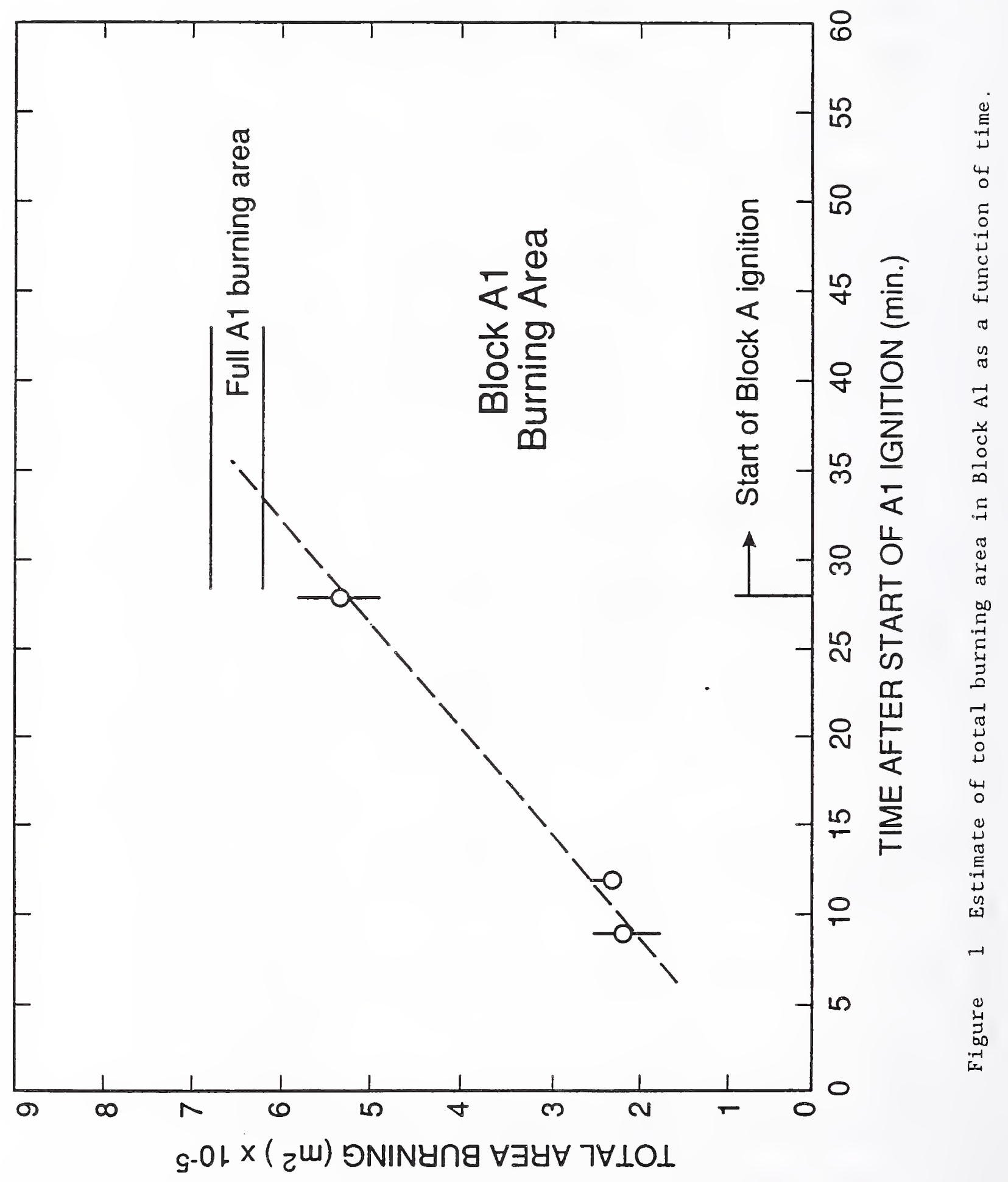




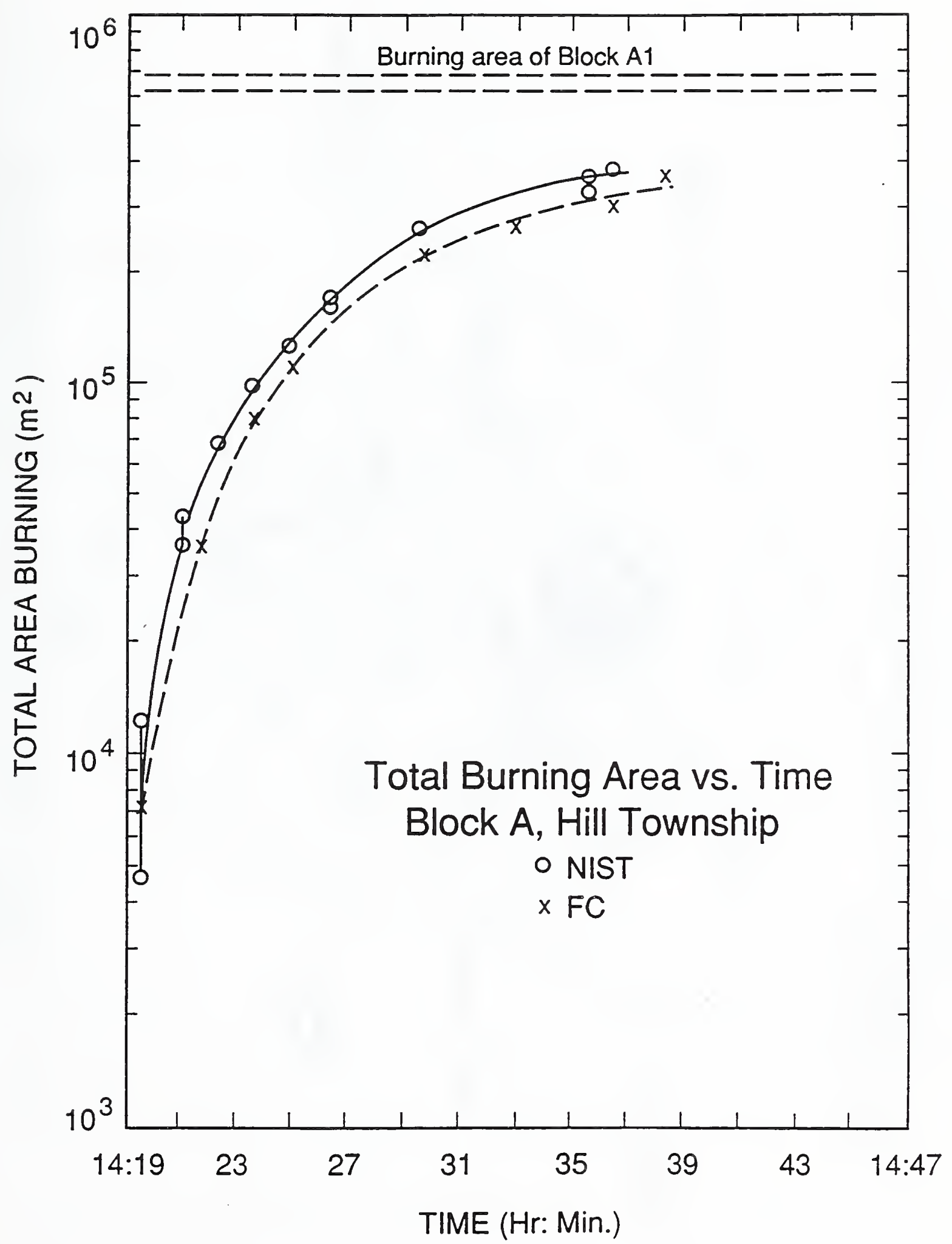

Figure 2 Total burning area in Block A versus time, as determined by NIST and by Forestry Canada from the infrared video tape. 


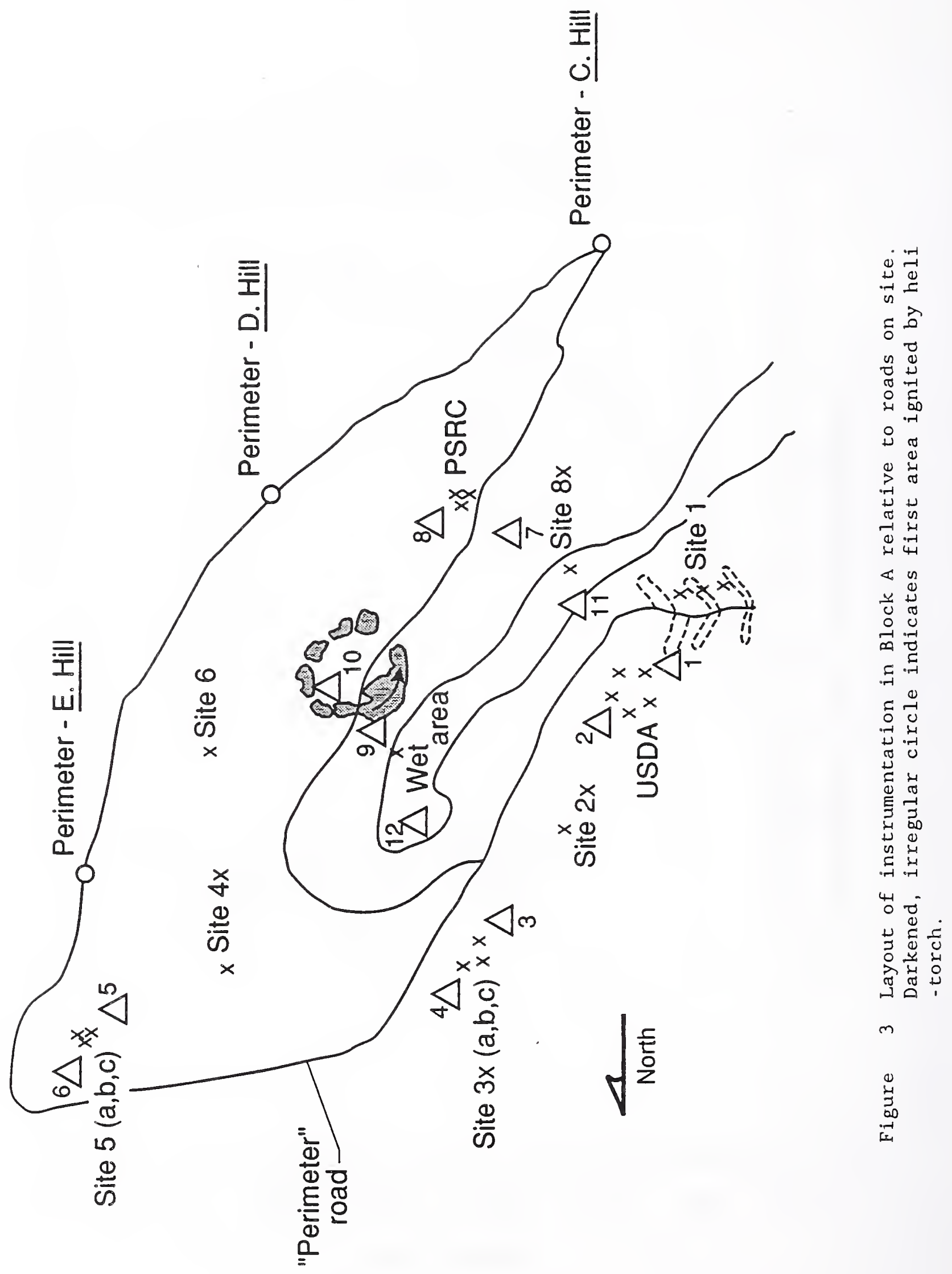




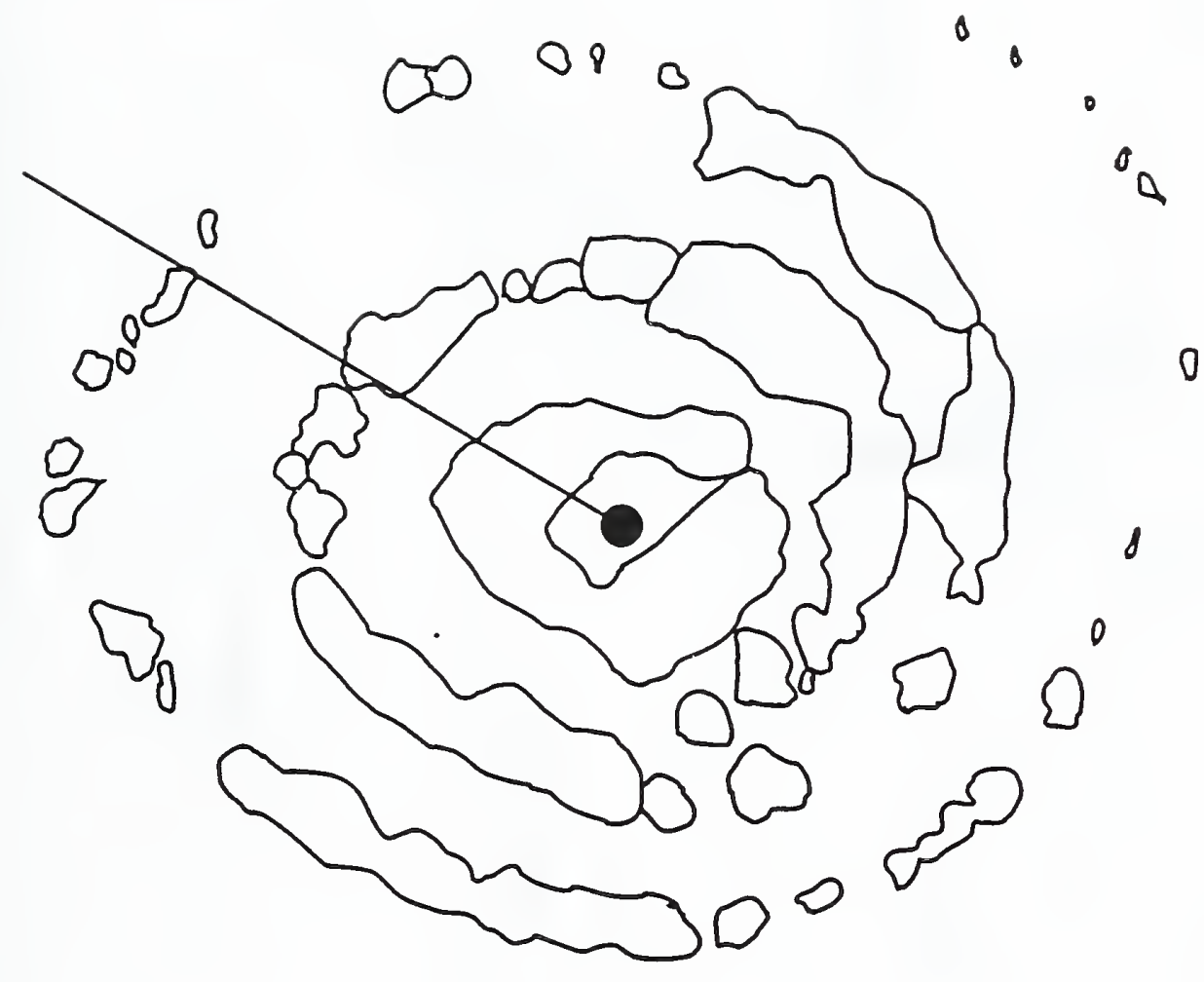

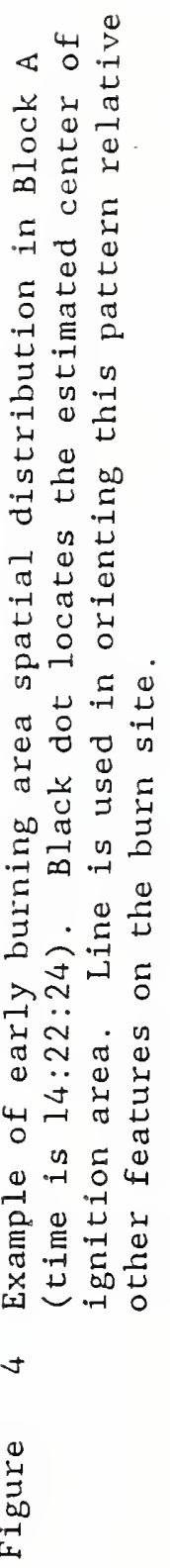




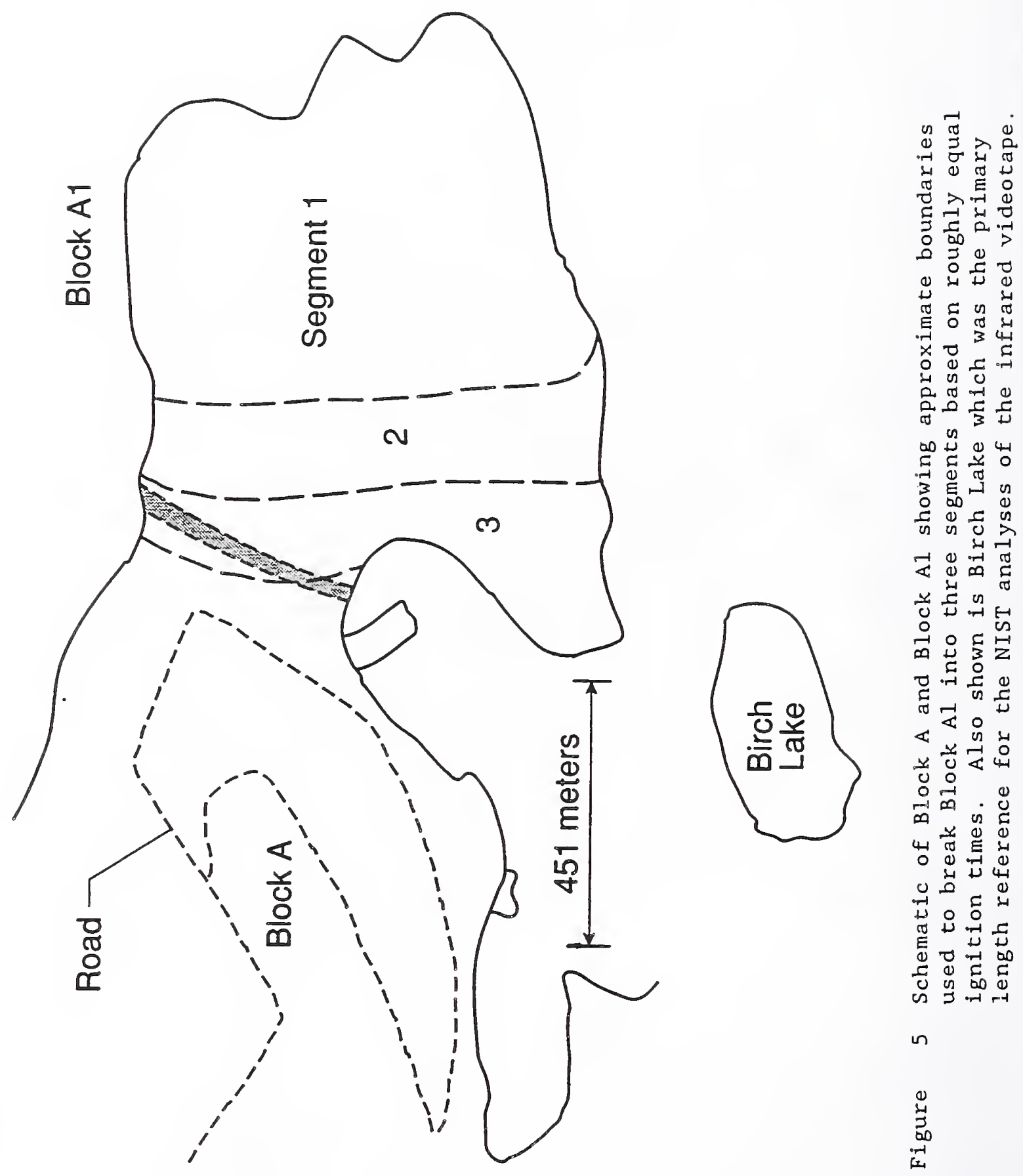




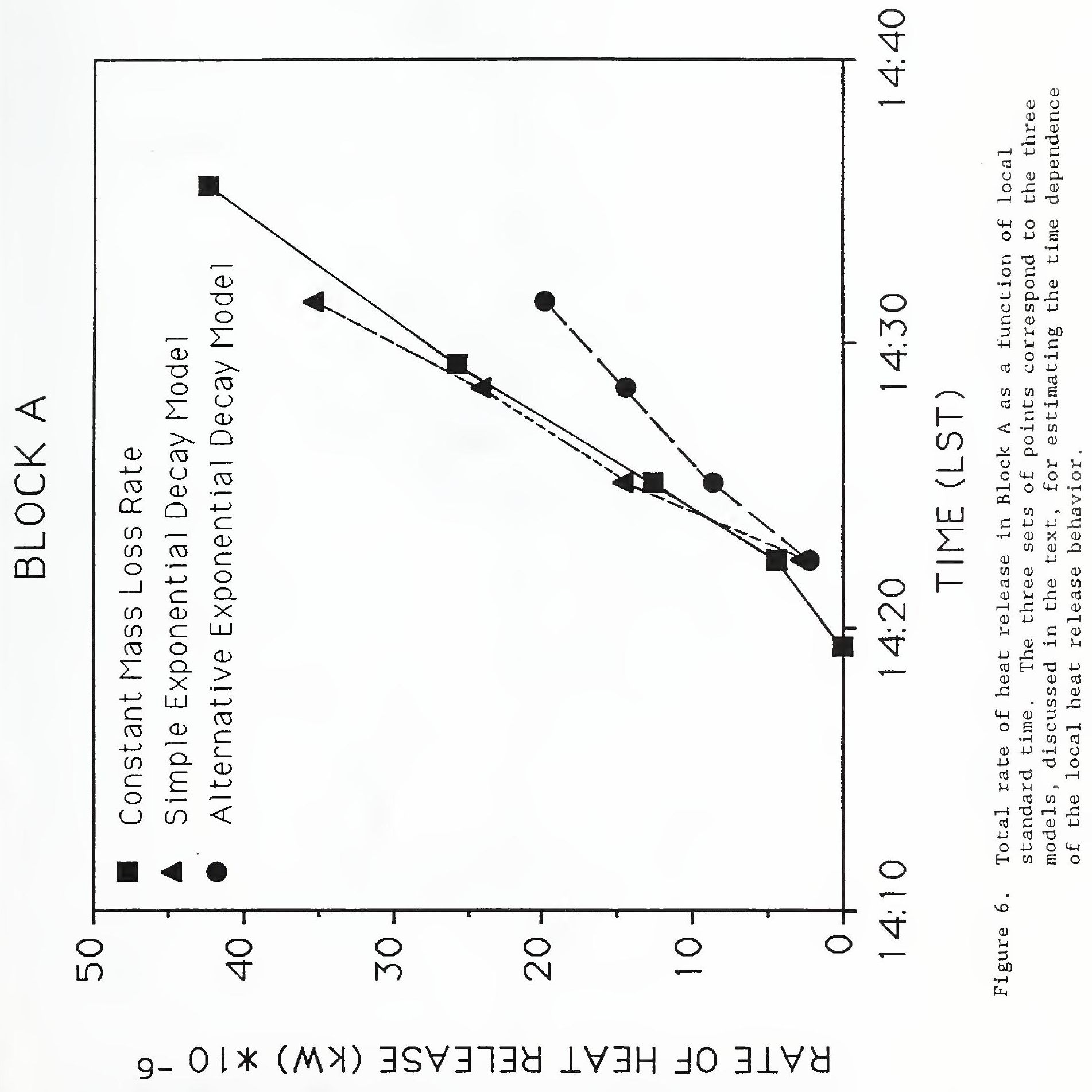



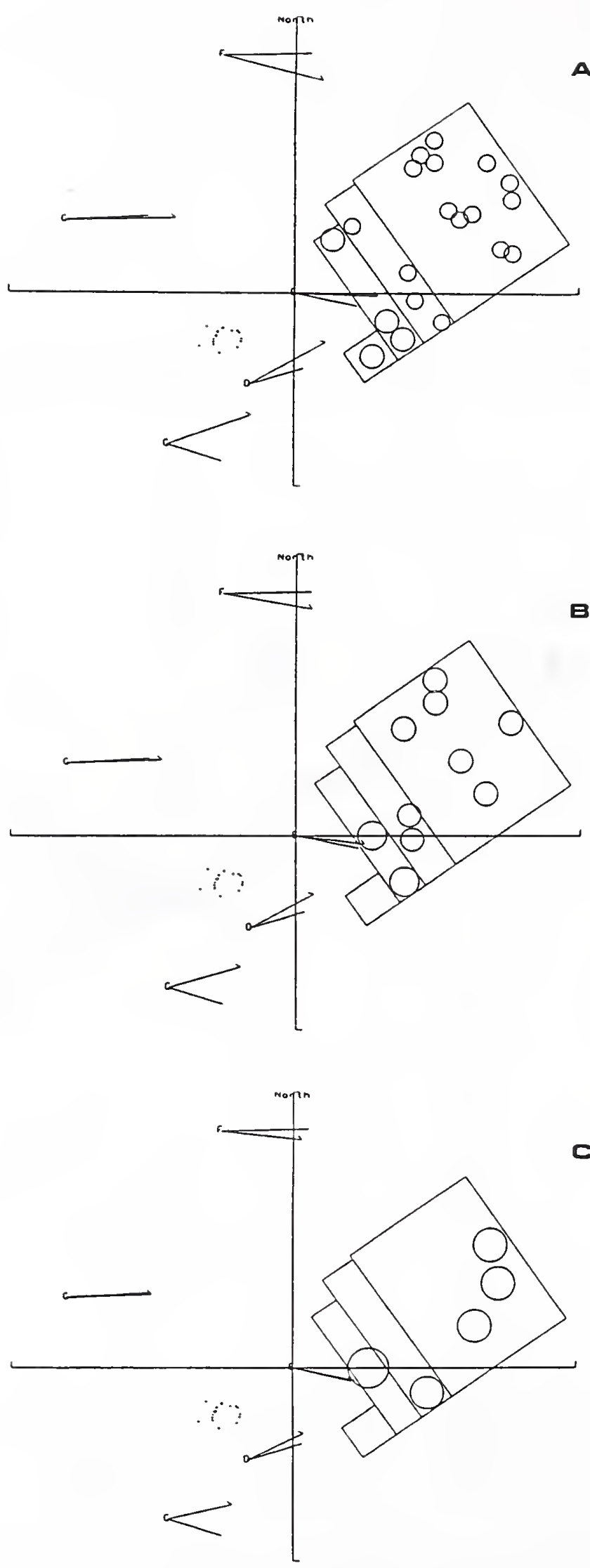

Figure 7 Comparison of calculated (line with arrow head) and measured (line without arrow head) velocity vectors at Forestry Canada anemometer locations at 14:19:20. Description of Block Al is being varied in (a), (b), and (c) to improve velocity vector matching. Version (c) is used for model calculations at next two times. 


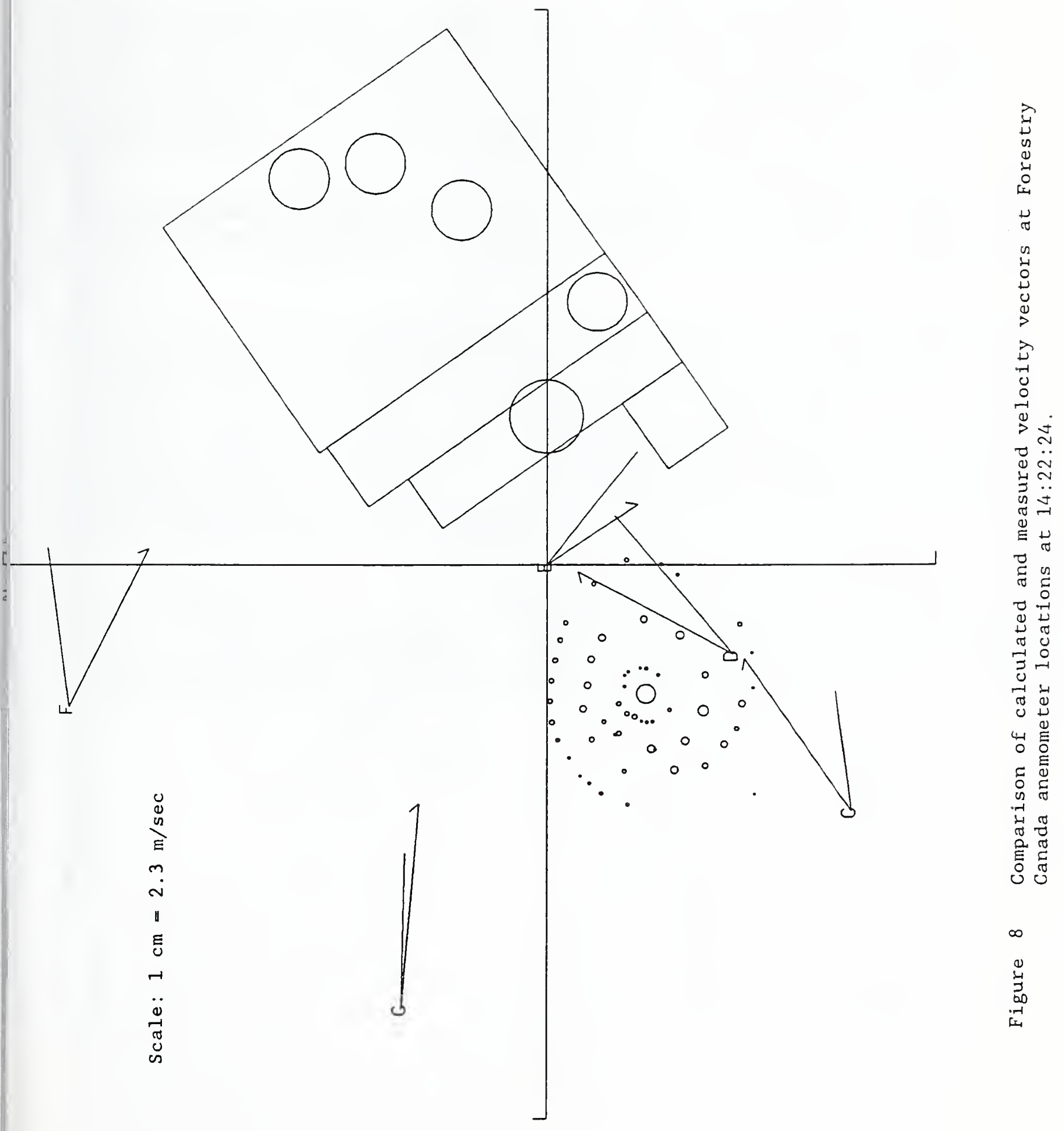




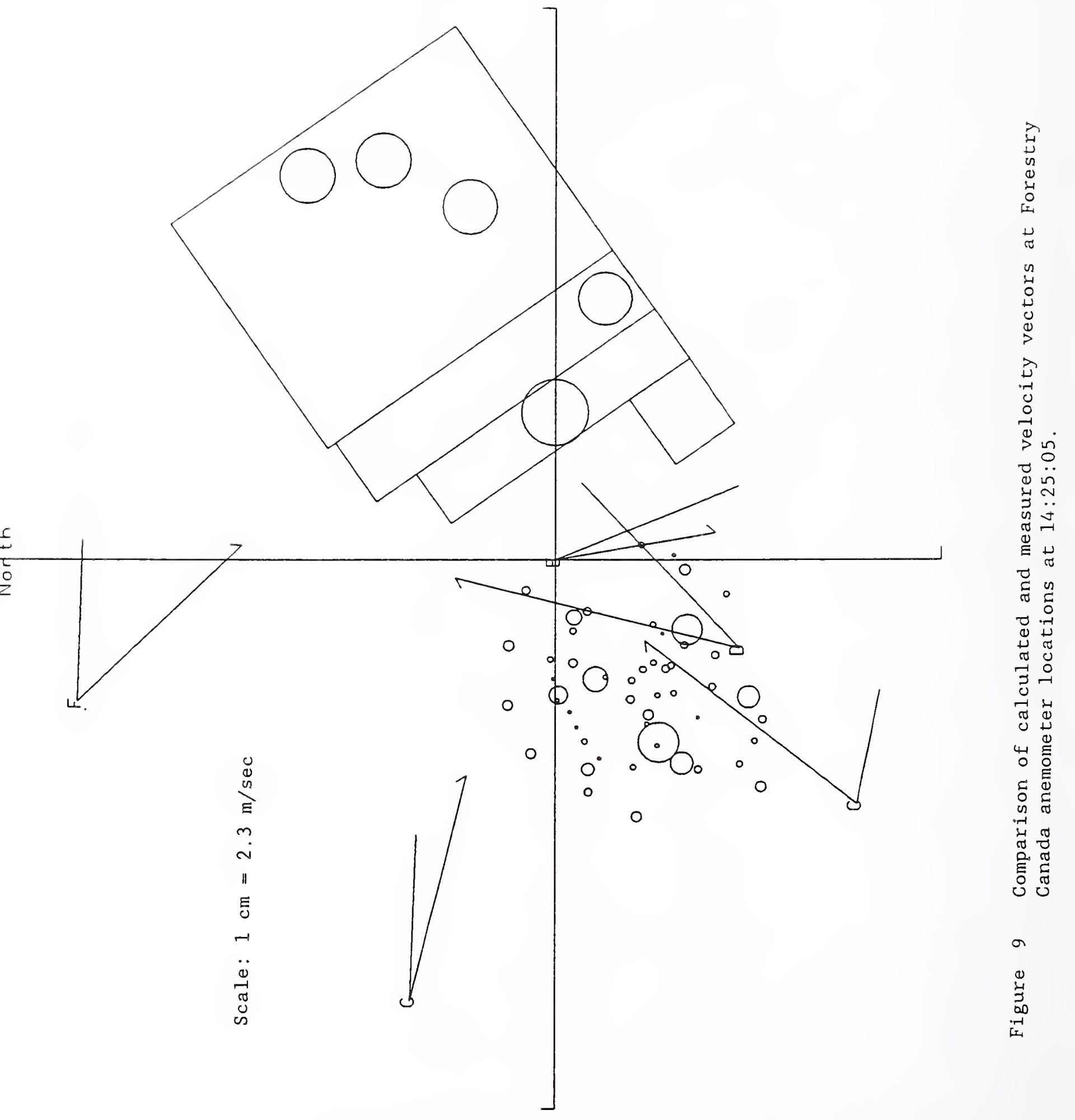




\section{Appendix \\ NIST Thermocouple Instrumentation}

The location of the NIST thermocouples was within the bounds of six of the Forestry Canada sampling triangles; this is illustrated schematically in Fig. A-1. Within each triangle the layout was as shown in Figure A-2. The details of the datalogger and thermocouple placement at each site are shown in Fig. A3. As noted in the caption there, the two thermocouples shown well above the ground were lowered to a few centimeters above the leaf litter to keep them more comparable to the Forestry Canada installations.

All of the dataloggers were started about one hour before the beginning of the ignition process. They record local temperature versus absolute time. The temperatures themselves are of less interest than what they reveal about the time of onset of flaming or smoldering and the duration of these two combustion stages.

Within any of the six instrumented triangles there were eight thermocouples. For each logger, two of the thermocouples were focussed mainly on the duff behavior. Thus, one thermocouple was placed just above the duff to sense flaming there; the other was placed in the duff to sense its smoldering behavior. The other pair of thermocouples for each logger was focussed somewhat higher in the fuel layer to sense flaming there. In some of the six triangles Forestry Canada also placed one or more of their thermologgers (generally at one or more sides of the triangle) in an arrangement similar to ours but without the outward extension of one of the thermocouples. The data from these two sources complement each other.

The thermocouples in any given triangle were at known spacings relative to each other. Thus they can be used to estimate the rate and direction of flame spread, at least for the domains in which the thermocouples were placed. These data should agree with similar results obtainable from the infrared camera looking down on the fire. 


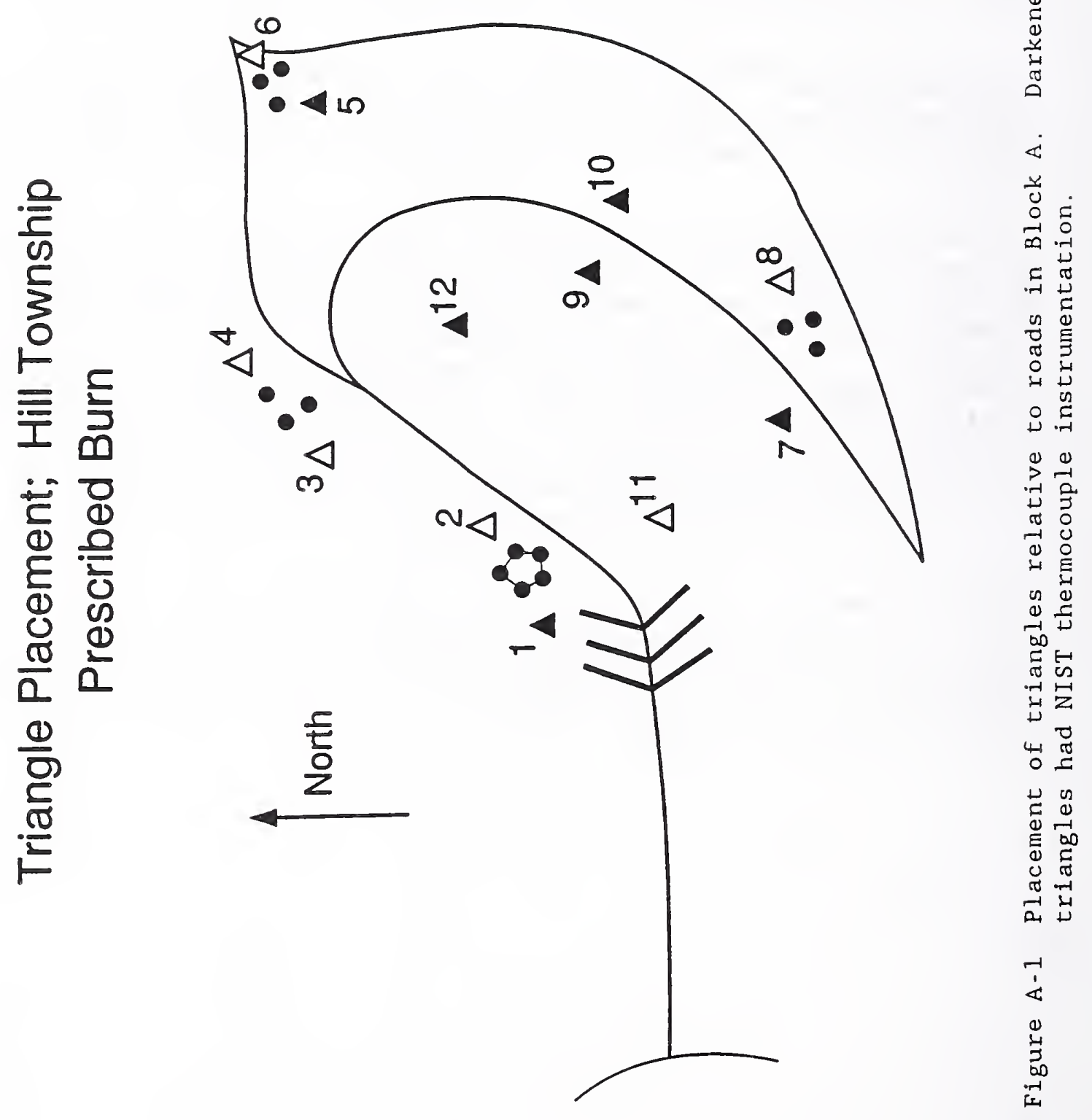




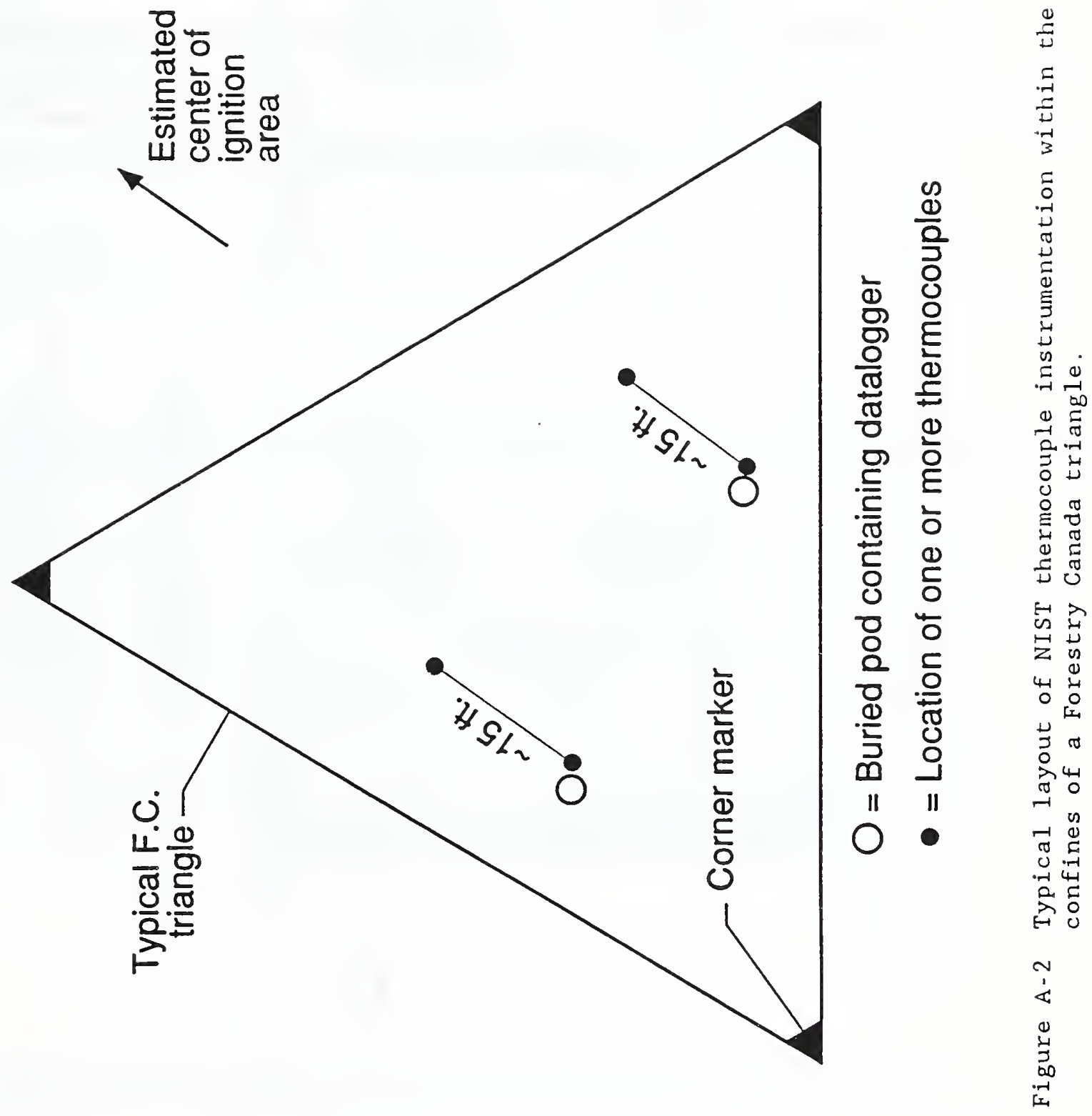




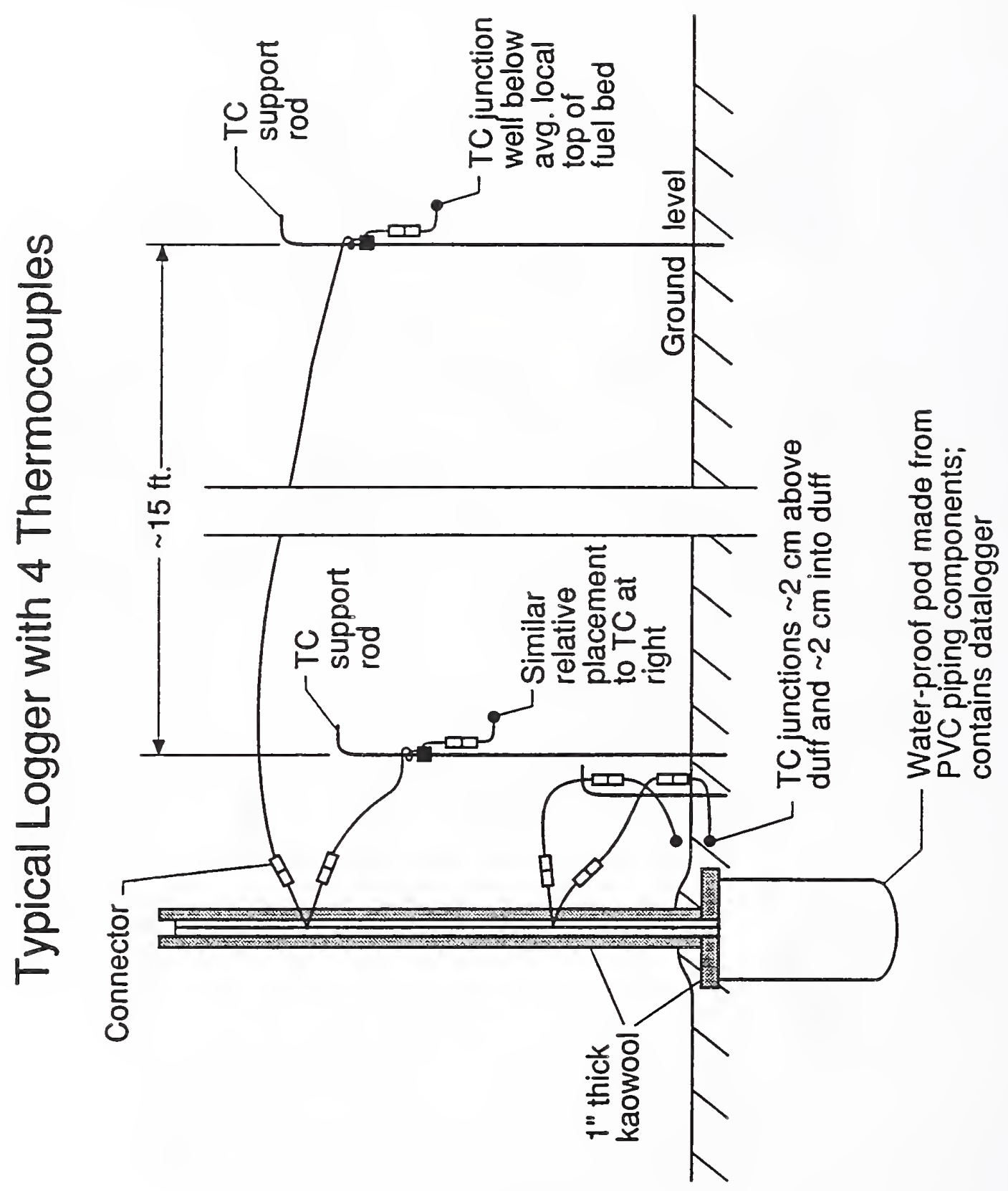

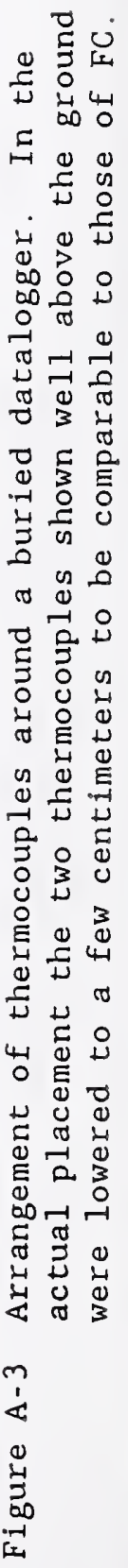


NIST-114A

(REV. 3-90)
U.S. DEPARTMENT OF COMMERCE

NATIONAL INSTITUTE OF STANDARDS AND TECHNOLOGY

BIBLIOGRAPHIC DATA SHEET
1. PUBLCATION OA REPORT NUMBEF

NISTIR 4430

2. PERFORMING ORGANIZATION REPORT NUMBEA

3. PUBLCATION DATE

October 1990

\section{TITLE AND SUBTITLE}

Estimation of the Rate of Heat Release and Induced

Wind Field in a Large Scale Fire.

5. AUTHOR(S)

T. J. Ohlemiller

D. Corley

6. PERFORMING ORGANIZATION (IF JOINT OR OTHER THAN MIST, SEE INSTRUCTIONS)

U.S. DEPARTMENT OF COMMERCE

NATIONAL INSTITUTE OF STANDARDS AND TECHNOLOQY

GAITHERSBURG, MD 20899

7. CONTRACT/GRANT NUMBER

8. TYPE OF REPORT AND PERIOD COVERED

\section{SPONSORING ORGANIZATION MAME AND COMPLETE ADDRESS (STAEET, CITY, STATE, ZIP)}

Defense Nuclear Agency

6801 Telegraph Road

Alexandria, VA 22310-3398

10. SUPPLEMENTAAY NOTES

11. ABSTRACT (A 200-WORD OR LESS FACTUAL SUMMARY OF MOST SIGNIFICANT INFORMATION. IF DOCUMENT INCLUDES A SIGNIFICANT BIBLIOGRAPHY OR UTERATURE SURVEY, MENTION IT HERE.)

Logging slash on a 486 hectare site in Ontario was burned as part of a Forestry Canada forest management program. A 100 hectare portion of this site was instrumented by several groups interested in large scale fires. The NIST Center for Fire Research utilized Forestry Canada data on mass loading before and after the fire, total burning area as a function of time and burning duration to estimate the spatial and temporal pattern of heat release during the burning of the instrumented section of the fire. Complete information necessary for making this estimate is lacking; the necessary assumptions and their accuracy (when known) are discussed. Heat release rate is reported for three different assumptions regarding the temporal behavior of flaming and smoldering phases of the combustion. This information is utilized in the context of a flow model due to Baum and McCaffrey to calculate the near ground flow field induced by this heat release pattern and the results are compared to the point measurements made in the field.

12. KEY WORDS (6 TO 12 ENTRIES; ALPHABETICAL ORDER; CAPITAUZE ONLY PROPER NAMES; AND SEPARATE KEY WORDS BY SEMICOLONS)

fire induced winds prescribed burn

forest fires heat release rate

large scale fire tests

FOR OFFICIAL DISTRIBUTION. DO NOT RELEASE TO NATIONAL TECHMICAL INFORMATION SERVICE (NTIS).

ORDER FROM SUPERINTENDENT OF DOCUMENTS, U.S. GOVERMMENT PRINTING OFFICE. WASHINGTON, DC 20402.

ORDER FROM NATIONAL TECHNICAL IMFORMATION SERVICE (NTIS), SPRINGFIELD, VA 22161.

14. MUMBER OF PRINTED PAGES

57

15. PAICE

$\mathrm{A} 04$ 


